University of Szeged

Bolyai Institute

Ahmed Mohsin Mahdi

\title{
Conical Curves in Constant Curvature Planes
}

\section{Ph.D. Dissertation}

\author{
Supervisor: DR. ÁRPÁD KURUSA \\ Doctoral School of Mathematics and Computer Science \\ Faculty of Science and Informatics
}

Szeged, 2020 
To my father's soul and my Brother's soul "Salam" you will remain in my heart as long as I live. My work with love and sincerity to your souls. 


\section{Contents}

$\begin{array}{lr}\text { Preface } & 1\end{array}$

1 Preliminaries and preparations $\quad 3$

1.1 Basic differential geometry . . . . . . . . . . . . . . . . . . . . 3

1.1 .1 Curves . . . . . . . . . . . . . . . . . . . . 3

1.1 .2 Surfaces ...................... . . . 4

1.1.3 Riemann manifolds . . . . . . . . . . . . . . . . . . . 6

1.1.4 Two-dimensional manifolds of constant curvature . . . . . . . . 7

1.2 Projective-metric spaces . . . . . . . . . . . . . . . . 8

1.2.1 Elliptic projective-metric planes . . . . . . . . . . . . . . . 9

1.2.2 Parabolic projective-metric planes . . . . . . . . . . . . . 10

1.2.3 Hyperbolic projective-metric planes . . . . . . . . . . . . . . . . . 11

1.2.4 Constant curvature planes . . . . . . . . . . . . . . . . . . 11

1.3 Classes of curves in the Euclidean plane . . . . . . . . . . . . . . . . . 12

1.3.1 Quadratic curves . . . . . . . . . . . . . . . . . . . 12

1.3 .2 Conic sections . . . . . . . . . . . . . . . . . . 13

1.3.3 Curves defined by sum or difference of distances . . . . . . . . . . 15

1.3.4 Curves defined by ratio of distances . . . . . . . . . . . . 15

$\begin{array}{llr}2 & \text { Conical curves with given properties } & 17\end{array}$

2.1 Quadratic conical curves in the hyperbolic plane . . . . . . . . . . . . . 17

2.2 Symmetric conical curves in the hyperbolic plane . . . . . . . . . . . . . 25

2.3 Quadratic conical curves on the sphere . . . . . . . . . . . . . 30

2.4 Symmetric conical curves on the sphere . . . . . . . . . . . . . . 36

2.5 Conical ellipses and conical hyperbolas . . . . . . . . . . . . . . . . . 39

$\begin{array}{lr}\text { Bibliography } & 40\end{array}$

$\begin{array}{ll}\text { Notations } & 41\end{array}$

$\begin{array}{ll}\text { Summary } & 42\end{array}$

Magyar nyelvü összefoglaló (Summary in Hungarian) 45

$\begin{array}{ll}\text { Acknowledgements } & 48\end{array}$

$\begin{array}{ll}\text { Declaration of Authorship } & 49\end{array}$ 


\section{Preface}

In a projective-metric space $(\mathcal{M}, d)$ we define

$\left(D_{1}\right)$ a conical curve as the set

$$
\mathcal{C}_{F, \mathcal{H}}^{\varepsilon}:=\left\{X \in \mathbb{R}^{n}: \varepsilon d(X, \mathcal{H})=d(F, X)\right\},
$$

where $\mathcal{H}$ is a hyperplane, the leading hyperplane or directrix, $F \notin \mathcal{H}$ is a point, the focus, and $\varepsilon>0$ is a number, the numeric eccentricity. A conical curve is said to be elliptic, parabolic and hyperbolic, if $\varepsilon<1, \varepsilon=1$ and $\varepsilon>1$, respectively.

For given fixed points $F_{1}, F_{2}$, the focuses, and number $a \neq d\left(F_{1}, F_{2}\right) / 2$, the radius, we define

$\left(D_{2}\right)$ the ellipsoid (ellipse in dimension 2) as the set

$$
\mathcal{E}_{d ; F_{1}, F_{2}}^{a}:=\left\{E: 2 a=d\left(F_{1}, E\right)+d\left(E, F_{2}\right)\right\} \text {, and }
$$

$\left(D_{3}\right)$ the hyperboloid (hyperbola in dimension 2) as the set

$$
\mathcal{H}_{d ; F_{1}, F_{2}}^{a}:=\left\{X: 2 a=\left|d\left(F_{1}, X\right)-d\left(X, F_{2}\right)\right|\right\},
$$

according to $a>d\left(F_{1}, F_{2}\right) / 2$ or $a<d\left(F_{1}, F_{2}\right) / 2$, respectively. Value $2 f:=d\left(F_{1}, F_{2}\right)$ is the eccentricity, and if the eccentricity vanishes, then the ellipsoid (ellipse) is called sphere (circle). Further, an ellipsoid (ellipse) or hyperboloid (hyperbola) is called conical if it is a conical curve.

According to [15], A. Moór raised the request for determining those Finsler manifolds in which the class of elliptic conical curves coincides with the class of ellipses, or the class of hyperbolic conical curves coincides with the class of hyperbolas. Tamássy and Bélteky found in [16, Theorem 2], that the only Finsler space where the class of elliptic conical curves coincides with the class of ellipses is the Euclidean space.

A similar problem was solved by Kurusa in [10, Theorem 6.1], where he proved that the only Minkowski geometry in which either a conical ellipsoid or a conical hyperboloid exists is the Euclidean one. At the end of his paper [10] Kurusa formulated the problem of determining projective-metric spaces in which

(a) some or all ellipses are conical, or

(b) some or all hyperbolas are conical. 
Kurusa's main result [10, Theorem 6.1] was based on that, by [10, Theorem 4.2 and 4.3], the only Minkowski geometry in which a symmetric conical curve exists is the Euclidean one. Additionally, it is also proved in [10, Theorem 5.1] that the only Minkowski plane in which a quadratic conical curve exists is the Euclidean one. So Kurusa also raised the request to determine the projective-metric spaces in which

(c) some or all elliptic conical curves are symmetric, or

(d) some or all hyperbolic conical curves are symmetric, or

(e) some or all elliptic conical curves are quadratic, or

(f) some or all hyperbolic conical curves are quadratic.

All these problems are open for curved projective-metric spaces, so it was natural to set the goal of the research to answer Kurusa's request for curved constant curvature spaces. We reached this goal and published the results in [11-13].

Our results are as follow:

Theorem A. If a conical curve $\mathcal{C}$ in a curved constant curvature plane $\mathcal{P}$ is symmetric, then $\mathcal{P}$ is the sphere and the focus of $\mathcal{C}$ is the pole of the directrix of $\mathcal{C}$.

Theorem B. If a conical curve $\mathcal{C}$ in a curved constant curvature plane $\mathcal{P}$ is quadratic, then $\mathcal{P}$ is the sphere and either the focus of $\mathcal{C}$ is the pole of the directrix of $\mathcal{C}$ or $\mathcal{C}$ is parabolic.

Theorem C. If $\mathcal{C}$ is a conical ellipse or a conical hyperbola in a curved constant curvature plane $\mathcal{P}$, then $\mathcal{P}$ is the sphere and the focus of $\mathcal{C}$ is the pole of the directrix of $\mathcal{C}$.

The presentation is based on my papers [11,12] and [13], but for the sake of a broader view we give precise definitions from the ground up, provide basic theorems for curves and surfaces, and describe thoroughly from both the projective and the differential geometric point of views the spaces used in the text to show the dual nature of the constant curvature spaces. 


\section{Chapter 1}

\section{Preliminaries and preparations}

In this chapter we collect definitions, theorems and some proofs which will be used as auxiliary facts for the next chapters.

Points of $\mathbb{R}^{n}$ are denoted as $A, B, \ldots$, vectors are $\overrightarrow{A B}$ or $\mathbf{a}, \mathbf{b}, \ldots$, but we use these latter notations also for points if the origin is fixed. The open segment with endpoints $A$ and $B$ is denoted by $\overline{A B}=(A, B), \bar{A} B$ is the open ray starting from $A$ passing through $B$, and $A B$ denotes the line through $A$ and $B$.

We denote the affine ratio of the collinear points $A, B$ and $C$ by $(A, B ; C)$ that satisfies $(A, B ; C) \overrightarrow{B C}=\overrightarrow{A C}$. The cross ratio of the collinear points $A, B$ and $C, D$ is $(A, B ; C, D)=(A, B ; C) /(A, B ; D)[4$, page 243].

Notations $\mathbf{u}_{\varphi}=(\cos \varphi, \sin \varphi)$ and $\mathbf{u}_{\varphi}^{\perp}:=(\cos (\varphi+\pi / 2), \sin (\varphi+\pi / 2))$ are frequently used.

\subsection{Basic differential geometry}

In this section we provide the basic definitions and theorems of differential geometry that are necessary to understand our results in the next chapter.

\subsubsection{Curves}

Definition 1.1. A parameterized differentiable curve is a differentiable map $\mathbf{p}: \mathcal{I} \rightarrow \mathbb{R}^{3}$ of an open interval $\mathcal{I}=(a, b)$ of the real line $\mathbb{R}$ into $\mathbb{R}^{3}$. 


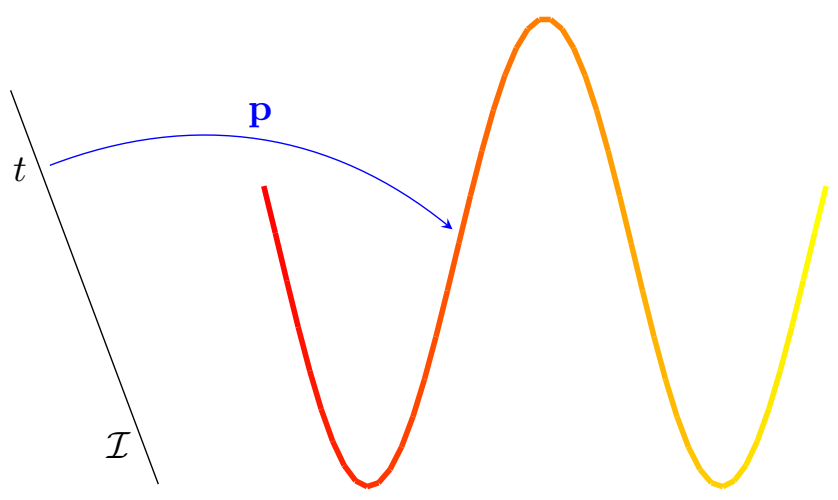

Figure 1.1: Curve and its parameterization

The differentiability means that $\mathbf{p}$ maps each $t \in \mathcal{I}$ into point $\mathbf{p}(t)=(x(t), y(t), z(t)) \in$ $\mathbb{R}^{3}$ in such a manner that the functions $x(t), y(t), y(t)$ are differentiable. The variable $t$ is called the parameter of the curve.

The vector $\mathbf{p}^{\prime}(t)=\left(x^{\prime}(t), y^{\prime}(t), z^{\prime}(t)\right) \in \mathbb{R}^{3}$ is the tangent vector of the curve $\mathbf{p}$ at $t$, and the image set $\mathbf{p} \subset \mathbb{R}^{3}$ is called the trace of $\mathbf{p}$.

Definition 1.2. A parameterized differentiable curve $\mathbf{p}: \mathcal{I} \rightarrow \mathbb{R}^{3}$ is said to be regular if $\mathbf{p}^{\prime}(t) \neq 0$ for all $t \in \mathcal{I}$. Then the vector $\mathbf{p}^{\prime}(t)$ is called the tangent vector of $\mathbf{p}$ at $\mathbf{p}(t)$ or at $t$.

Definition 1.3. The arc length of a regular parameterized curve $\mathbf{p}$ from the point $\mathbf{p}\left(t_{0}\right)$ to $\mathbf{p}\left(t_{1}\right)$ is

$$
s(t)=\int_{t_{0}}^{t_{1}}\left|\mathbf{p}^{\prime}(t)\right| d t, \text { where }\left|\mathbf{p}^{\prime}(t)\right|=\sqrt{\left(x^{\prime}(t)\right)^{2}+\left(y^{\prime}(t)\right)^{2}+\left(z^{\prime}(t)\right)^{2}} .
$$

A regular parameterized curve $\mathbf{p}$ is said to be arc length parameterized if $\left|\mathbf{p}^{\prime}(s)\right|=1$.

Definition 1.4. Let $\mathbf{p}: \mathcal{I} \rightarrow \mathbb{R}^{3}$ be a curve parameterized by arc length. The number $\left|\mathbf{p}^{\prime \prime}(s)\right|=\kappa(s)$ is called the curvature of $\mathbf{p}$ at $\mathbf{p}(s)$ or simply at $s$.

\subsubsection{Surfaces}

Definition 1.5. A subset $\mathcal{S} \subset \mathbb{R}^{3}$ is a regular surface if for each point $S \in \mathcal{S}$ there exists a neighborhood $\mathcal{V} \subseteq \mathbb{R}^{3}$ and a map $\mathbf{r}: U \rightarrow V \cap \mathcal{S}$ of an open set $\mathcal{U} \subseteq \mathbb{R}^{2}$ onto $\mathcal{V} \cap \mathcal{S} \subseteq \mathbb{R}^{3}$ such that

(1) the coordinate functions $x, y, z$ of $\mathbf{r}(u, v)=(x(u, v), y(u, v), z(u, v))((u, v) \in U)$, have continuous partial derivatives of all orders;

(2) the inverse $\overline{\mathbf{r}}: \mathcal{V} \cap \mathcal{S} \rightarrow U$ is well defined and is continuous;

(3) (The regularity condition.) the derivative $\dot{\mathbf{r}}$ is one to one. 


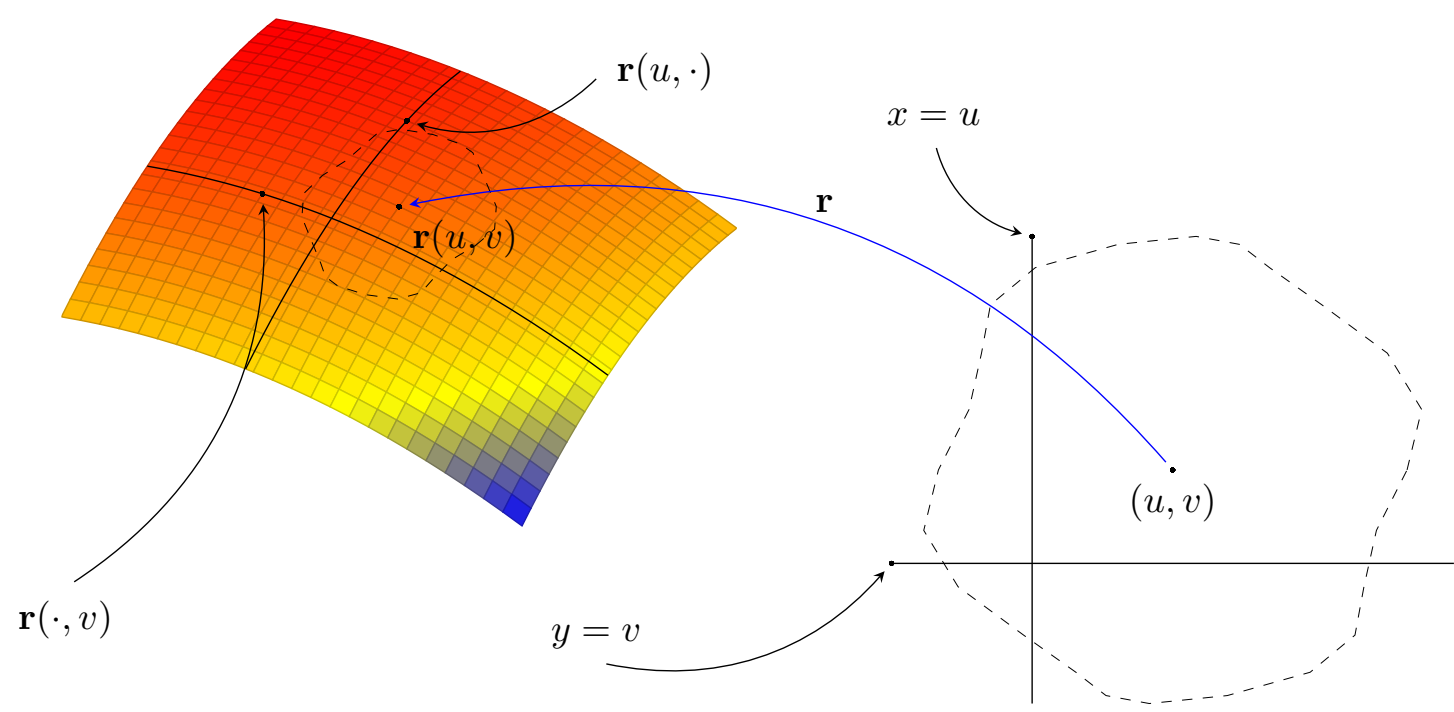

Figure 1.2: Surface and its parameterization

Proposition 1.6. If $f: \mathcal{U} \rightarrow \mathbb{R}$ is a differentiable function on an open set $\mathcal{U} \subseteq \mathbb{R}^{2}$, then the graph of $f$, that is, the subset of $\mathbb{R}^{3}$ given by $(x, y, f(x, y))$ for $(x, y) \in U$, is a regular surface.

Proposition 1.7. If $f: \mathcal{U} \subseteq \mathbb{R}^{3} \rightarrow \mathbb{R}$ is a differentiable function and $a \in f(\mathcal{U})$ is a regular value of $f$, then $f^{-1}(\mathcal{U})$ is a regular surface in $\mathbb{R}^{3}$

Example 1.1. The ellipsoid

$$
\frac{x^{2}}{a^{2}}+\frac{y^{2}}{b^{2}}+\frac{z^{2}}{c^{2}}=1
$$

is a regular surface by Proposition 1.7 because it is the set $f^{-1}(0)$ where

$$
f(x, y, z)=\frac{x^{2}}{a^{2}}+\frac{y^{2}}{b^{2}}+\frac{z^{2}}{c^{2}}-1
$$

is a differentiable function, and 0 is a regular value of $f$.

Example 1.2. The hyperboloid of two sheets $-x^{2}-y^{2}+z^{2}=1$ is a regular surface, since it is given by $f^{-1}(0)$, where 0 is a regular value of $f(x, y, z)=-x^{2}-y^{2}+z^{2}-1$.

Proposition 1.8. Let $\mathcal{S} \subseteq \mathbb{R}^{3}$ be a regular surface and $P \in \mathcal{S}$. Then there exists a neighborhood $\mathcal{V} \subseteq \mathcal{S}$ of $P$ such that $\mathcal{V}$ is the graph of a differentiable function which has one of the following three forms $z=f(x, y), y=g(x, z), x=h(y, z)$.

Definition 1.9. The set $T \mathcal{S}$ of the tangent vectors of the curves on the surface $\mathcal{S}$ is called the tangent bundle. The set $T_{P} \mathcal{S}$ of tangent vectors $\mathbf{p}^{\prime}(t) \in T \mathcal{S}$, where $\mathbf{p}(t)=P$, is called the tangent plane of $\mathcal{S}$ at $P \in \mathcal{S}$.

Every tangent plane $T_{P} \mathcal{S}$ is a 2-dimensional vector space. For every tangent vector $\mathbf{v} \in T_{P} \mathcal{S}$ there are a great many curves $\mathbf{p}$ on the surface $\mathcal{S}$ that satisfies $\mathbf{p}(0)=P$ and $\mathbf{v}=\mathbf{p}^{\prime}(0)$. 
Definition 1.10. A differentiable map $f: \mathcal{S} \rightarrow \mathbb{R}$ is called differentiable scalar field on $\mathcal{S}$. The differential $\partial_{\mathbf{v}} f$ of the scalar field $f$ evaluated against the tangent vector $\mathbf{v} \in T_{P} \mathcal{S}$ is the derivative $(f \circ \mathbf{p})^{\prime}(0)$, where $\mathbf{p}$ is a curve on the surface $\mathcal{S}$ satisfying $\mathbf{p}(0)=P$ and $\mathbf{v}=\mathbf{p}^{\prime}(0)$.

We notice that the differential of a scalar field evaluated against a tangent vector does not depend on the choice of the curve chosen in the definition.

Definition 1.11. A differentiable map $X: \mathcal{S} \rightarrow T \mathcal{S}$ is called differentiable vector field on $\mathcal{S}$, if $X(P) \in T_{P} \mathcal{S}$ for every $P \in \mathcal{S}$. The vector space of the differentiable vector fields on $\mathcal{S}$ is denoted by $T_{*} \mathcal{S}$.

Definition 1.12. The Lie-bracket $[X, Y]$ of two vector fields $X, Y \in T_{*} \mathcal{S}$ is a linear mapping of scalar fields defined by $f \mapsto[X, Y] f=\partial_{X}\left(\partial_{Y} f\right)-\partial_{Y}\left(\partial_{X} f\right)$.

\subsubsection{Riemann manifolds}

We consider only Riemannian manifolds given on surfaces of the 3-dimensional space.

Definition 1.13. The pair $(\mathcal{S}, g)$ is called a Riemannian manifold of dimension 2 , if $\mathcal{S}$ is a regular surface and $g: \mathcal{S} \ni P \mapsto g_{P}$ provides a Euclidean product $g_{P}: T_{P} \mathcal{S} \times T_{P} \mathcal{S} \rightarrow \mathbb{R}$ at every point $P \in \mathcal{S}$ on the corresponding tangent plane $T_{P} \mathcal{S}$ such that if $X$ and $Y$ are differentiable vector fields on $\mathcal{S}$, then the function $\mathcal{S} \ni P \mapsto g_{P}(X(P), Y(P))$ is a smooth function of $P$. The function $g$ is called a Riemannian metric (or Riemannian metric tensor).

Every surface with its tangent planes equipped with the Euclidean product $g_{P}(\mathbf{u}, \mathbf{v}):=$ $\langle\mathbf{u}, \mathbf{v}\rangle$ given by the restriction of the Euclidean product $\langle\cdot, \cdot\rangle$ of the space $\mathbb{R}^{3}$ is such a Riemannian manifold of dimension 2. The Riemannian metric given in this way called inherited Riemannian metric.

Definition 1.14. The length of a differentiable curve $\mathbf{p}:(a, b) \rightarrow \mathcal{S} \subset \mathbb{R}^{3}$ in a Riemannian manifold $(\mathcal{S}, g)$ is $\ell(\mathbf{p}):=\int_{a}^{b} \sqrt{g_{\mathbf{p}(t)}(\dot{\mathbf{p}}(t), \dot{\mathbf{p}}(t))} d t$.

Definition 1.15. The Riemannian distance function $d_{g}: \mathcal{S} \times \mathcal{S} \ni(P, Q) \mapsto d_{g}(P, Q) \in$ $\mathbb{R}$ on a Riemannian manifold $(\mathcal{S}, g)$ is $\inf _{\mathbf{p} \in \mathcal{C}_{P, Q}} \ell(\mathbf{p})$, where $\mathcal{C}_{P, Q}$ is the set of all the differentiable curve $\mathbf{p}$ in the Riemannian manifold $(\mathcal{S}, g)$ connecting $P$ and $Q$.

A Riemannian manifold with the Riemannian distance function is a metric space.

Definition 1.16. A bilinear mapping $\nabla: T_{*} \mathcal{S} \times T_{*} \mathcal{S} \ni(X, Y) \rightarrow \nabla_{X} Y \in T_{*} \mathcal{S}$ is called affine connection if for all differentiable functions $f: \mathcal{S} \rightarrow \mathbb{R}$ and for all vector fields $X, Y \in T_{*} \mathcal{S}$ if $\nabla_{f X} Y=f \nabla_{X} Y$ (functional linearity in the first variable) and $\nabla_{X}(f Y)=$ $\partial_{X} f Y+f \nabla_{X} Y$ (Leibniz rule in the second variable) hold. 
An affine connection is called torsion-free if $[X, Y]=\nabla_{X} Y-\nabla_{Y} X$ for every $X, Y \in T_{*} \mathcal{S}$.

Definition 1.17. An affine connection is a Levi-Civita connection if it is torsion-free, and compatible with the Riemannian metric $g$, i.e. $\nabla_{X}(g(Y, Z))=g\left(\nabla_{X} Y, Z\right)+g\left(Y, \nabla_{X} Z\right)$.

There is always a unique Levi-Civita connection that is easy to prove through the Koszul formula $2 g\left(\nabla_{X} Y, Z\right)=\partial_{X}(g(Y, Z))+\partial_{Y}(g(Z, X))-\partial_{Z}(g(X, Y))$.

Definition 1.18. The Riemannian curvature is the trilinear mapping $\mathrm{R}$ of vector fields to vector fields defined by $\mathrm{R}(X, Y) Z=\nabla_{X} \nabla_{Y} Z-\nabla_{Y} \nabla_{X} Z-\nabla_{[X, Y]} Z$.

The Riemannian curvature is a tensor, because $\mathrm{R}(f X, Y) Z=\mathrm{R}(X, f Y) Z=\mathrm{R}(X, Y)(f Z)=$ $f \mathrm{R}(X, Y) Z$ for every scalar field $f$ and vector fields $X, Y, Z$, hence $\mathrm{R}(X, Y) Z(P)$ depends in fact only on the vectors $X(P), Y(P), Z(P) \in T_{P} \mathcal{S}$. Further, the expression $\kappa(\mathbf{u}, \mathbf{v})=\frac{g_{P}(\mathrm{R}(\mathbf{u}, \mathbf{v}) \mathbf{v}, \mathbf{u})}{g_{P}(\mathbf{u}, \mathbf{u}) g_{P}(\mathbf{v}, \mathbf{v})-g_{P}^{2}(\mathbf{u}, \mathbf{v})}$ does not depend on the independent vectors $\mathbf{u}, \mathbf{v} \in T_{P} \mathcal{S}$.

Definition 1.19. The value $\kappa_{P}=\kappa(\mathbf{u}, \mathbf{v})$ is called the (sectional) curvature of $(\mathcal{S}, g)$ at the point $P \in \mathcal{S}$.

\subsubsection{Two-dimensional manifolds of constant curvature}

It is easy to see that the plane and the sphere with their respective inherited Riemannian metric are surfaces of constant curvature, but there is a third example worth noting.

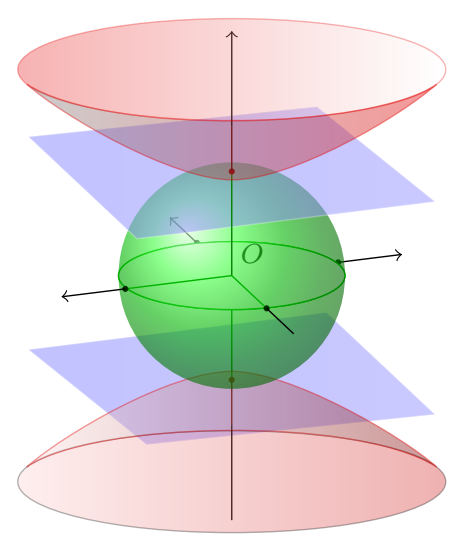

Let the surface $\mathcal{K}_{\kappa}^{2} \subset \mathbb{R}^{3}$ of points $\boldsymbol{p}=\left(p_{1}, p_{2}, p_{3}\right)$ satisfying

$$
\kappa\left(p_{1}^{2}+p_{2}^{2}\right)+p_{3}^{2}=1
$$

where $\kappa \in\{1,0,-1\}$. Equip the surface $\mathcal{K}_{\kappa}^{2}$ with the Riemannian metric $g_{\kappa}$ such that

$$
g_{\kappa ; \boldsymbol{p}}: T_{\boldsymbol{p}} \mathcal{K}_{\kappa}^{2} \times T_{\boldsymbol{p}} \mathcal{K}_{\kappa}^{2} \ni(\boldsymbol{x}, \boldsymbol{y}) \mapsto x_{1} y_{1}+x_{2} y_{2}+\kappa x_{3} y_{3}
$$

for every point $\boldsymbol{p} \in \mathcal{K}_{\kappa}^{2}$. Then the pairs $\left(\mathcal{K}_{\kappa}^{2}, g_{\kappa}\right)$ have constant curvature $\kappa$.

If $\kappa \geq 0$, then the Riemannian metric in (1.2) is the inherited metric, and we have the sphere $\mathcal{K}_{1}^{2}$ and two planes $\mathcal{K}_{0}^{2}$. The Riemannian manifold $\left(\mathcal{K}_{-1}^{2}, g_{-1}\right)$ is a different case: both sheets of the hyperboloid $\mathcal{K}_{-1}^{2}$ equipped with the Riemannian metric $g_{-1}$ model the hyperbolic plane, but $g_{-1}$ is not the inherited metric.

Theorem 1.20 ([19, Hilbert's theorem]). There exists no complete regular surface $\mathcal{S}$ of constant negative curvature in $\mathbb{R}^{3}$. 
Then one gets the so-called projective model $\overline{\mathcal{K}}_{\kappa}^{2}$ of the constant curvature space $\mathbb{K}_{\kappa}^{2}$ of curvature $\kappa \in\{1,0,-1\}$ [5], and also the canonical correspondence

$$
\chi_{\kappa}: \mathcal{K}_{\kappa}^{2} \ni E \rightarrow\{E,-E\} \in \overline{\mathcal{K}}_{\kappa}^{2} \cong \mathbb{K}_{\kappa}^{2}
$$

by identifying the points of $\mathcal{K}_{\kappa}^{2} \subset \mathbb{R}^{3}$ that are symmetric in the origin.

\section{$1.2 \quad$ Projective-metric spaces}

Real projective plane $\mathbb{P}^{2}$ arises in several different ways.

Considering the real affine plane $\mathbb{R}^{2}$, we call the equivalence sets of the straight lines by parallelism ideal points, and add these points to the set of the usual (real) points of $\mathbb{R}^{2}$ so that each ideal point becomes a common point of every straight line belonging to that particular ideal point. This extended geometry is the real projective plane.

Another method to construct real projective plane $\mathbb{P}^{2}$ is to think of the straight lines passing through the origin $(0,0,0)$ in $\mathbb{R}^{3}$ as projective points, and think of the planes passing through the origin $(0,0,0)$ in $\mathbb{R}^{3}$ as projective straight lines.

A more algebraic way is to consider the equivalence classes of the non-vanishing directional vectors by the equivalency relation $\sim$ that relates two non-vanishing directional vectors equivalent $\sim$ if one of them is a scalar multiple of the other one. This leads to the homogeneous coordinates which is a coordinatization of the real projective plane $\mathbb{P}^{2}$.

Finally, an intuitive way of considering the real projective plane is to identify diametrical points of the sphere, i.e. these pairs constitute the points of the real projective plane.

A metric space is an ordered pair $(\mathcal{M}, d)$ such that $\mathcal{M}$ is a set, the set of points, and $d: \mathcal{M} \times \mathcal{M} \rightarrow \mathbb{R}$ is a metric, i.e. for any three points $x, y, z \in \mathcal{M}$ it satisfies $d(x, y)=$ $0 \Leftrightarrow x=y, d(x, y)=d(y, x)$, and $d(x, z) \leq d(x, y)+d(y, z)$, the triangle inequality.

If the metric space $(\mathcal{M}, d)$ is that $\mathcal{M}$ is a projective plane $\mathbb{P}^{2}$, or an affine plane $\mathbb{R}^{2} \subset \mathbb{P}^{2}$, or a (not necessarily bounded) proper open convex subset of an affine plane $\mathbb{R}^{2} \subset \mathbb{P}^{2}$, and the metric $d$ is complete, continuous with respect to the usual topology of $\mathbb{P}^{n}$, additive on the segments, and the geodesic lines of $d$ are exactly the non-empty intersection of $\mathcal{M}$ with the straight lines, then the pair $(\mathcal{M}, d)$ is called projective-metric space ${ }^{1}$ [4, p. 115].

Such projective-metric planes are called elliptic, parabolic, or hyperbolic, respectively, according to whether $\mathcal{M}$ is $\mathbb{P}^{2}, \mathbb{R}^{2}$, or a proper convex subset of $\mathbb{R}^{2}$. The projectivemetric planes of the latter two types are called straight [3, p. 1].

\footnotetext{
${ }^{1}$ Determining the projective-metric spaces and studying the individual ones is known as Hilbert's fourth problem.
} 
The geodesics of a projective-metric space of elliptic type have equal lengths, so we can set their length to $\pi$ by simply multiplying the metric with an appropriate positive constant. Therefore we assume from now on that projective-metric spaces of elliptic type have geodesics of length $\pi$.

Let $\ell$ be a line in $(\mathcal{M}, d)$ and let $P \in \mathcal{M}$ be a point outside of $\ell$. A point $P^{\perp} \in \ell$ is the $\ell$-foot of $P$, if $d(P, X) \geq d\left(P, P^{\perp}\right)$ for every $X \in \ell$. A line $\ell$ intersecting line $\ell^{\prime}$ in a point $S$ is said to be perpendicular to $\ell$ if $S$ is an $\ell$-foot of $P$ for every $P \in \ell^{\prime} \backslash\{S\}$. We denote this relation by $\ell^{\prime} \perp \ell$, and notice, that $\perp$ is not necessarily a symmetric relation.

Every isometry of $(\mathcal{M}, d)$ is a restriction of a projectivity of the projective space $\mathbb{P}^{n}[3]$. They leave perpendicularity invariant, because perpendicularity is determined by the metric.

A set $\mathcal{S} \subset \mathcal{M}$ is called symmetric about a point $C$, if $X \in \mathcal{S}$ if and only if $Y \in \mathcal{S}$, where $C$ is in the metric midpoints of the segment $\overline{X Y}$, i.e. $2 d(X, C)=2 d(C, Y)=d(X, Y)$.

\subsubsection{Elliptic projective-metric planes}

Every elliptic plane can be constructed in the following way. Take a Euclidean metric on $\mathbb{R}^{2}$ and let $\langle\cdot, \cdot\rangle$ be its Euclidean product. Define the function $\hat{\delta}: \mathcal{S}^{2} \times \mathcal{S}^{2} \rightarrow \mathbb{R}$ by

$$
\hat{\delta}(\boldsymbol{x}, \boldsymbol{y})=\arccos \langle\boldsymbol{x}, \boldsymbol{y}\rangle
$$

This is a metric on $\mathcal{S}^{2}$, and it satisfies the strict triangle inequality, i.e. $\hat{\delta}(A, B)+$ $\hat{\delta}(B, C)=\hat{\delta}(A, C)$ if the points $A, B$ and $C$ are in a hemisphere. Equality happens if and only if $B$ is on the great circle determined by $A$ and $C$. If the diametrical points are identified and the metric is inherited, then we get an elliptic plane.

The isometries of $\left(\mathcal{S}^{2}, \hat{\delta}\right)$ are the restrictions of those isometries of the Euclidean plane $\left(\mathbb{R}^{2},\langle\cdot, \cdot\rangle\right)$ that leave $\mathcal{S}^{2}$ invariant: the orthogonal transforms $O(2)$. Any orthogonal transform is a product of at most 3 reflections in planes, and any two non-degenerate triangles with pair-wisely equal side-lengths determine one and only one $\hat{\delta}$-isometry that maps the first of these triangles onto the second one.

Perpendicularity in the elliptic plane is a symmetric relation, because the great circles $\ell^{\prime}$ and $\ell$ are perpendicular to each other if and only if the 2-dimensional planes they span are orthogonal with respect to $\langle\cdot, \cdot\rangle$.

To show that the constructed geometry is an elliptic projective-metric space, we use the gnomonic projection [18] $\Gamma_{O}: \mathcal{S}^{2} \rightarrow T_{O} \mathcal{S}^{2}$ of the sphere, where $O \in \mathcal{S}^{2}$ and $T_{O} \mathcal{S}^{2}$ is the tangent hyperplane of $\mathcal{S}^{2}$ at point $O$ with the projective extension. 


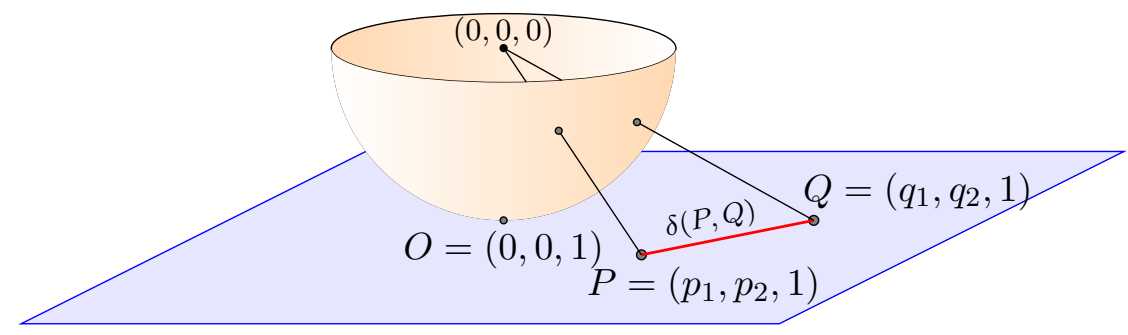

$\Gamma_{O}$ projects the spherical metric $\hat{\delta}$ to the metric

$$
\delta: \mathbb{R}^{n-1} \times \mathbb{R}^{n-1} \rightarrow[0, \pi) \quad(P, Q) \mapsto \hat{\delta}(P, Q)=\arccos \left(\frac{\langle P, Q\rangle}{|P||Q|}\right) .
$$

\subsubsection{Parabolic projective-metric planes}

The most important parabolic projective-metric planes are the Minkowski planes ${ }^{2}$. They are constructed in the following way.

Let $\mathcal{I}$ be an open, strictly convex, bounded domain in $\mathbb{R}^{2}$, (centrally) symmetric to the origin. Then the function $d: \mathbb{R}^{2} \times \mathbb{R}^{2} \rightarrow \mathbb{R}$ defined by

$$
d(\boldsymbol{x}, \boldsymbol{y})=\inf \{\lambda>0:(\boldsymbol{y}-\boldsymbol{x}) / \lambda \in \mathcal{I}\}
$$

is a metric on $\mathbb{R}^{2}[4, \mathrm{IV} .24]$, and is called Minkowski metric on $\mathbb{R}^{2}$. It satisfies the strict triangle inequality, i.e. $d(A, B)+d(B, C)=d(A, C)$ is valid if and only if $B \in \overline{A C}$.

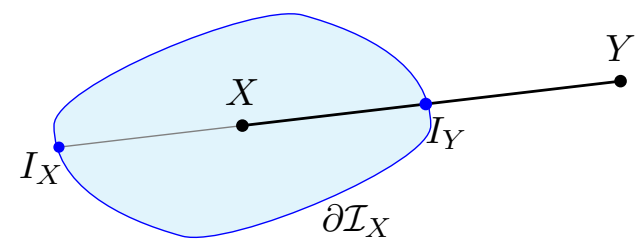

The pair $\left(\mathbb{R}^{2}, d\right)$ is the Minkowski plane, and $\mathcal{I}$ is called the indicatrix of it.

The isometries of a Minkowski plane $\left(\mathbb{R}^{2}, d\right)$ are the restrictions of those affine transforms of $\mathbb{R}^{2}$ that leave $\mathcal{I}$ invariant.

A line $\ell$ is perpendicular to a line $\ell^{\prime}$ if and only if $\ell^{\prime}$ is tangent at the point $\ell \cap \ell^{\prime}$ to $\mathcal{I}_{X}$ for a point $X \in \ell$, where $\mathcal{I}_{X}$ is a translated copy of $\mathcal{I}$ centered at point $X$.

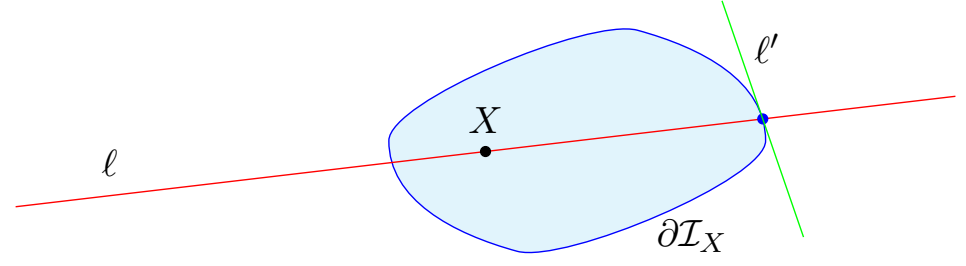

Perpendicularity in a Minkowski plane is a symmetric relation if and only if the boundary $\partial \mathcal{I}$ of the indicatrix is a Radon curve [14].

\footnotetext{
${ }^{2}$ They are also known as normed planes.
} 


\subsubsection{Hyperbolic projective-metric planes}

The most important hyperbolic projective-metric planes are the Hilbert planes. They are constructed in the following way.

If $\mathcal{M}$ is an open, strictly convex, proper subset of $\mathbb{R}^{2}$, then the function $d: \mathcal{M} \times \mathcal{M} \rightarrow \mathbb{R}$ defined by

$$
d(A, B)= \begin{cases}0, & \text { if } A=B, \\ \frac{1}{2}|\ln (A, B ; C, D)|, & \text { if } A \neq B, \text { where } \overline{C D}=\mathcal{M} \cap A B,\end{cases}
$$

is a metric on $\mathcal{M}[4$, page 297] which satisfies the strict triangle inequality, i.e. $d(A, B)+$ $d(B, C)=d(A, C)$ if and only if $B \in \overline{A C}$.

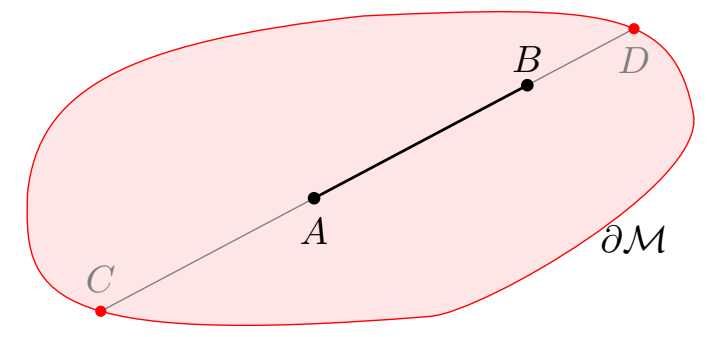

The pair $(\mathcal{M}, d)$ is the Hilbert plane, $\mathcal{M}$ is its domain, and the function $d$ is called the Hilbert metric on $\mathcal{M}$.

The isometries of a Hilbert plane $(\mathcal{M}, d)$ are the restrictions of those projective transforms of $\mathbb{P}^{2}$ that leave $\mathcal{M}$ invariant.

A line $\ell$ in $\mathcal{M}$ is perpendicular to a line $\ell^{\prime}$ if and only if $\ell^{\prime}$ connects the point $\ell \cap \ell^{\prime}$ of $\mathcal{M}$ and the intersection of the tangents of $\mathcal{M}$ that touch $\mathcal{M}$ at the points $\partial \mathcal{M} \cap \bar{\ell}$, where $\bar{\ell}$ is the Euclidean line containing $\ell$.

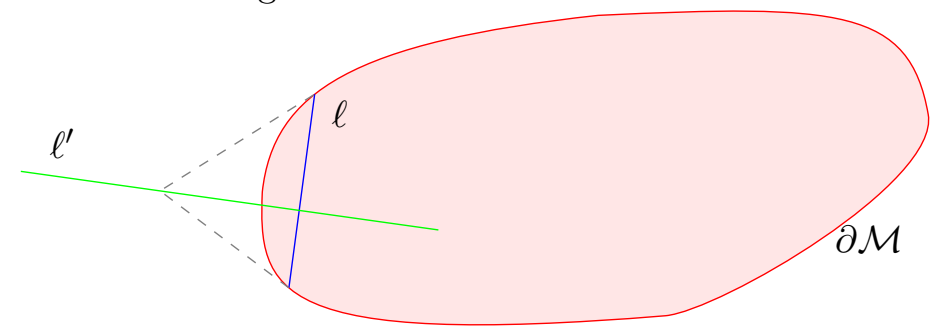

Perpendicularity in a Minkowski plane is a symmetric relation if and only if the boundary $\partial \mathcal{M}$ is an ellipse [8].

\subsubsection{Constant curvature planes}

There are special elliptic, parabolic and hyperbolic projective-metric planes that make Riemannian manifolds. 
It is clear that a Minkowski plane is Euclidean if and only if its indicatrix is an ellipse.

It is known [4, (29.3)] that a Hilbert plane is a model of the hyperbolic plane of Bolyai, Lobachevskii and Gauss, if and only if its domain is the interior of an ellipse. Such Hilbert planes are called Cayley-Klein models of the hyperbolic plane.

It happens that these have constant curvature, and can also be constructed by the gnomonic projection of the 2 -dimensional manifolds $\left(\mathcal{K}_{\kappa}^{2}, g_{\kappa}\right)[9]$, where $\kappa \in\{0, \pm 1\}$.

The isometry groups of all these three constant curvature planes are generated by reflections in straight lines. Moreover specifically, we have

Theorem 1.21 ([4]). Every isometry of each of these three constant curvature planes can be given as a product of at most three reflections in straight lines.

This statement can be reversed in a sense:

(1) If the isometry group is generated by the reflections in a Minkowski plane, then the Minkowski plane is Euclidean.

(2) If the isometry group is generated by the reflections in a Hilbert plane, then the Hilbert plane is a hyperbolic plane.

\subsection{Classes of curves in the Euclidean plane}

In the Euclidean plane there are four differently defined classes of curves which however coincide in most of the cases. Here we briefly describe these classes to shade light over the problem considered in the main part of this thesis. We notice though that despite of the usual treatment we present, most parts would give clearer picture if considered in projective geometry.

\subsubsection{Quadratic curves}

The curves presented in this subsection are independent from the metric.

A curve in the plane is called quadratical, if it is part of a quadric

$$
\mathcal{Q}_{\mathfrak{s}}^{\sigma}:=\left\{(x, y):\left\{\begin{array}{ll}
1=x^{2}+\sigma y^{2}, & \text { if } \sigma \in\{-1,1\}, \\
x=y^{2}, & \text { if } \sigma=0,
\end{array}\right\},\right.
$$

where $\mathfrak{s}$ is an affine coordinate system. A quadric is called ellipse (affine circle), parabola and hyperbola, if $\sigma=1, \sigma=0$ and $\sigma=-1$, respectively. 

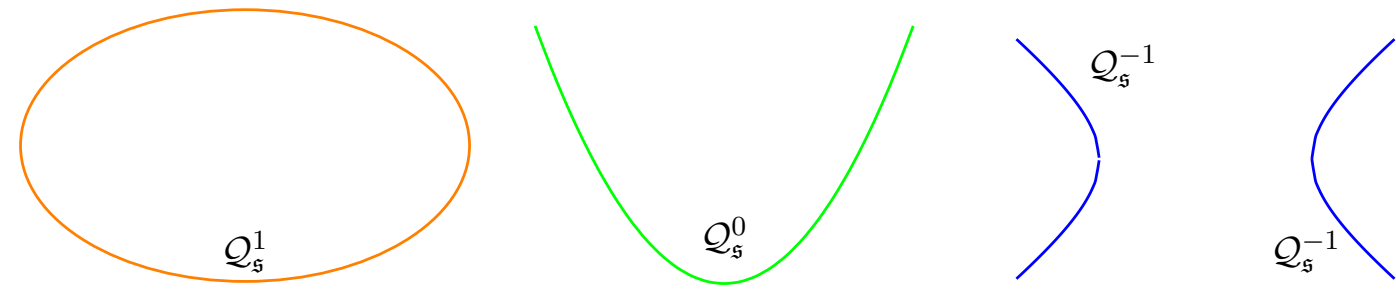

The ellipse is the only bounded conical curve, and it is such that any complete set of parallel lines has a member line which intersect the ellipse in exactly two points.

The parabola is a connected conical curve and that has exactly one complete set of parallel lines such that its every member line intersects the parabola in exactly one point.

The hyperbola is two connected curves (called branches) and it is such that exactly two complete sets of parallel lines are such that their every member line, except the one called asymptote, intersects the hyperbola in exactly one point.

\subsubsection{Conic sections}

Although it could be discussed in affine, or even better in projective geometry, in this section we present the subject in the Euclidean geometry. Notice however, that the metric is only used to formulate what a circular cone is, i.e. it could be formulated as an elliptic quadratic cone in affine space or as a quadratic cone in projective space.

Definition 1.22. Let a point, the apex, and two different lines, the axis and a generating line, be given in the space. Turning the generating line about the axis scours a surface called rotational or circular (double) cone (with two nappes).

The lines obtained while turning the generating line are called generating line too.

Definition 1.23. A curve obtained as the intersection of a plane, the cutting plane, with a cone is called conic section. A conic section is called elliptic, parabolic, and hyperbolic, if the cutting plane is parallel with 0,1 , and 2 generating line, respectively.

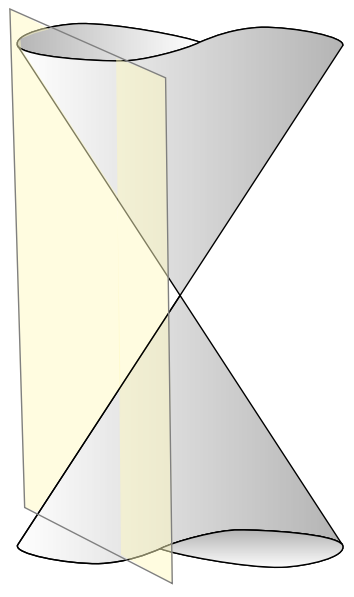

Planes that pass through the apex of the cone intersect the cone in a point, in a generating line or in a pair of generating lines. These are called degenerate conic sections. 

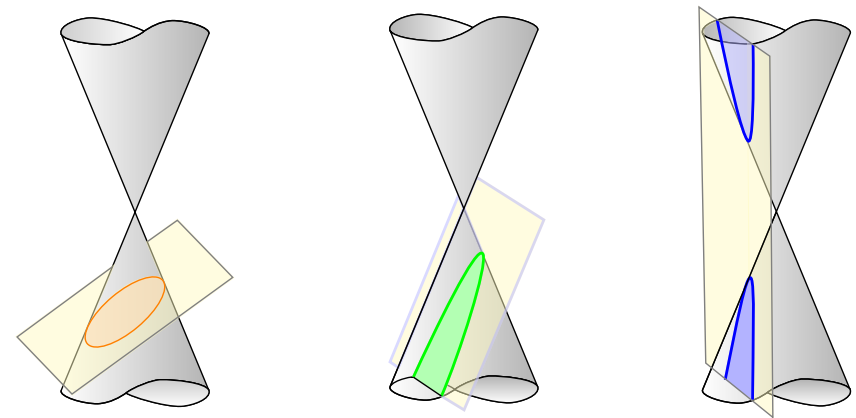

Every non-degenerate elliptic conic section is a bounded closed curve contained in one halves of the cone. The non-degenerate elliptic conic section are affine ellipses $\mathcal{Q}_{\mathfrak{s}}^{1}$, and also metric ellipses $\mathcal{E}_{F_{1}, F_{2}}^{a}$. Further, every affine ellipse $\mathcal{Q}_{\mathfrak{s}}^{1}$ can be constructed as a nondegenerate elliptic conic section.

Every non-degenerate parabolic conic section is an unbounded connected curve contained in one halves of the cone. The non-degenerate parabolic conic sections are affine parabolas $\mathcal{Q}_{\mathfrak{s}}^{0}$. Further, every affine parabola $\mathcal{Q}_{\mathfrak{s}}^{0}$ can be constructed as a non-degenerate parabolic conic section.

Every non-degenerate hyperbolic conic section has points in both halves of the cone, so they have two separate unbounded connected curves, the branches. The non-degenerate hyperbolic conic sections are affine hyperbolas $\mathcal{Q}_{\mathfrak{s}}^{-1}$, and also metric hyperbolas $\mathcal{H}_{F_{1}, F_{2}}^{a}$. Further, every affine hyperbola $\mathcal{Q}_{\mathfrak{s}}^{-1}$ can be constructed as a non-degenerate hyperbolic conic section.

A very effective method to consider plane sections of a circular cone in Euclidean space is to put Dandelin spheres [17] into the cone. Each Dandelin sphere touches the cone in a circle whose plane intersects the cutting plane of the corresponding conic section in a (maybe ideal) line, the directrix. A point of the cutting plane where the cutting plane touches a Dandelin sphere is called foci.
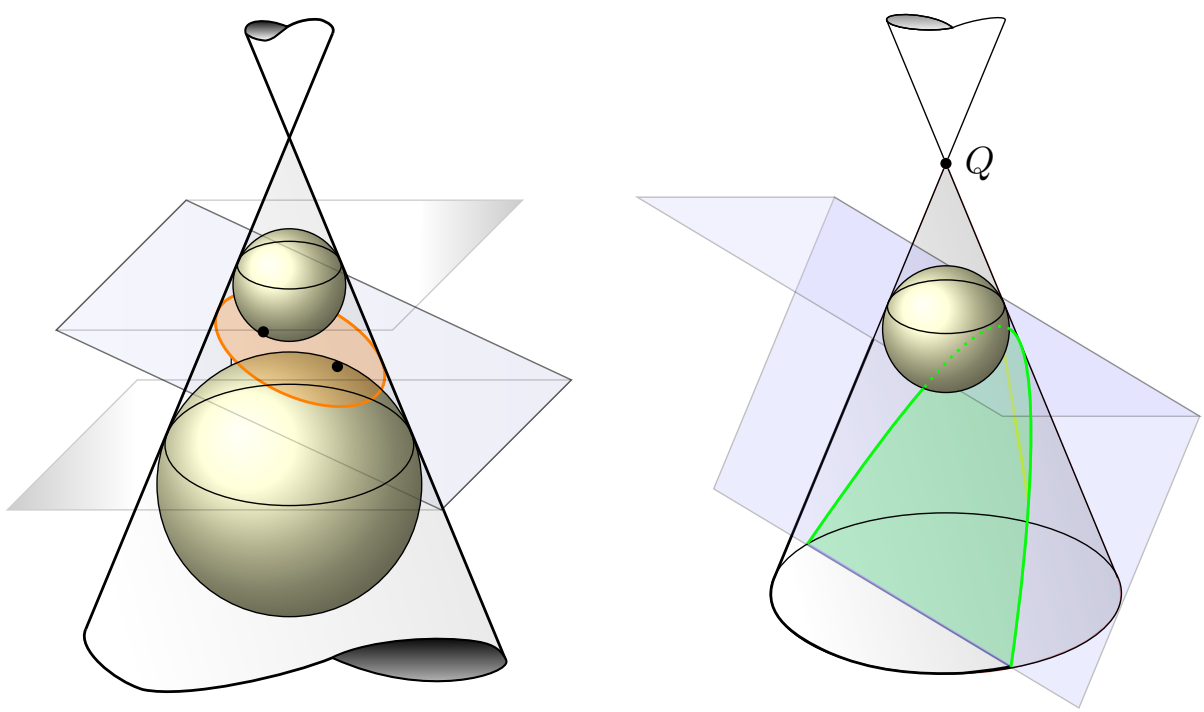


\subsubsection{Curves defined by sum or difference of distances}

The curves presented in this section are bound to the metric. For now, we stay in Euclidean geometry.

A closed segment $\overline{F_{1} F_{2}}$ of the different points $F_{1}, F_{2}$ are the locus of points $P$ in the plane such that the sum of the distances from $P$ to the two fixed points $F_{1}$ and $F_{2}$ is the constant $d\left(F_{1}, F_{2}\right)$.

Definition 1.24. An ellipse $\mathcal{E}_{F_{1}, F_{2}}^{a}$ is the locus of points $P$ in the plane such that the sum of the distances from $P$ to the two fixed points $F_{1}$ and $F_{2}$, the foci, is a constant $a>d\left(F_{1}, F_{2}\right)$. An ellipse $\mathcal{E}_{C, C}^{r}$ is called circle of radius $r$ with center $C$.

The closed rays $F_{1} F_{2} \backslash \overline{F_{1} F_{2}}$ of the different points $F_{1}, F_{2}$ is the locus of points $P$ in the plane such that the absolute value of the difference of the distances from $P$ to the two fixed points $F_{1}$ and $F_{2}$ is the constant $d\left(F_{1}, F_{2}\right)$.

Definition 1.25. A hyperbola $\mathcal{H}_{F_{1}, F_{2}}^{a}$ is the locus of points $P$ in the plane such that the absolute value of the difference of the distances from $P$ to the two fixed points $F_{1}$ and $F_{2}$, the foci, is a constant $a<d\left(F_{1}, F_{2}\right)$.
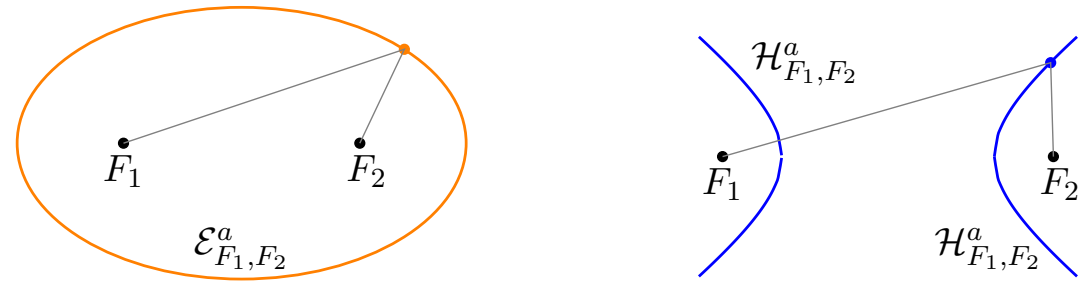

Every ellipse is an affine ellipse $\mathcal{Q}_{\mathfrak{s}}^{1}$, and every affine ellipse $\mathcal{Q}_{\mathfrak{s}}^{1}$ is the circle $\mathcal{E}_{(0,0),(0,0)}^{1}$ in the Euclidean metric $d$ defined by the inner product $\langle(x, y),(z, t)\rangle=x z+y t$.

Every hyperbola $\mathcal{H}_{F_{1}, F_{2}}^{a}$ is an affine hyperbola $\mathcal{Q}_{\mathfrak{s}}^{-1}$, and every affine hyperbola $\mathcal{Q}_{\mathfrak{s}}^{-1}$ is the hyperbola $\mathcal{H}_{(2,0),(-2,0)}^{2}$ in the Euclidean metric $d$.

\subsubsection{Curves defined by ratio of distances}

In this section we consider curves which are bound to the metric, for now, it is the Euclidean metric.

Definition 1.26. Given a positive number $\varepsilon$, the numerical eccentricity, a straight line $\ell$, the directrix, and a point $F \notin \ell$, the foci, in the plane, the conical curve $\mathcal{C}_{F, \ell}^{\varepsilon}$ is the locus of points $P$ in the plane such that $d(F, P)=\varepsilon d(P, \ell)$. 


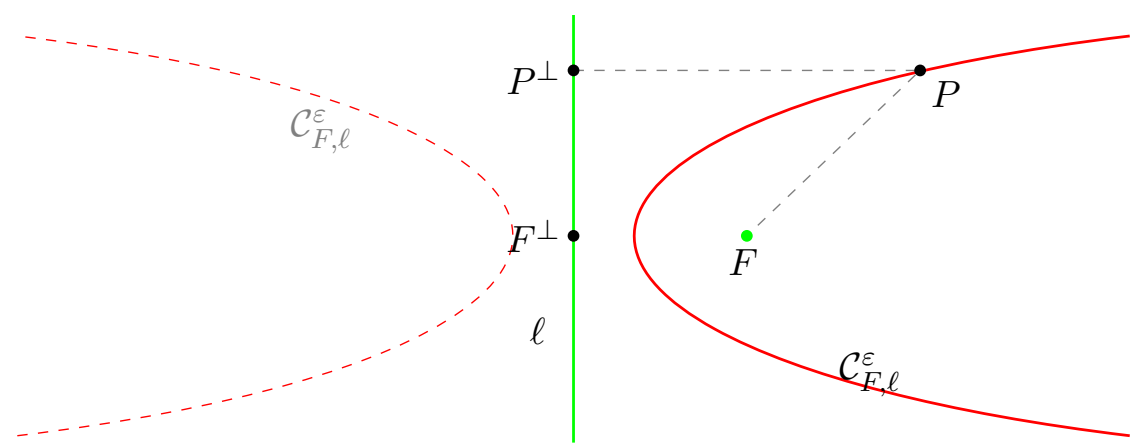

Figure 1.3: Conical curve in Euclidean plane

Definition 1.27. A conical curve is called elliptic, parabolic, and hyperbolic, if $\varepsilon<1$, $\varepsilon=1$, and $\varepsilon>1$, respectively.
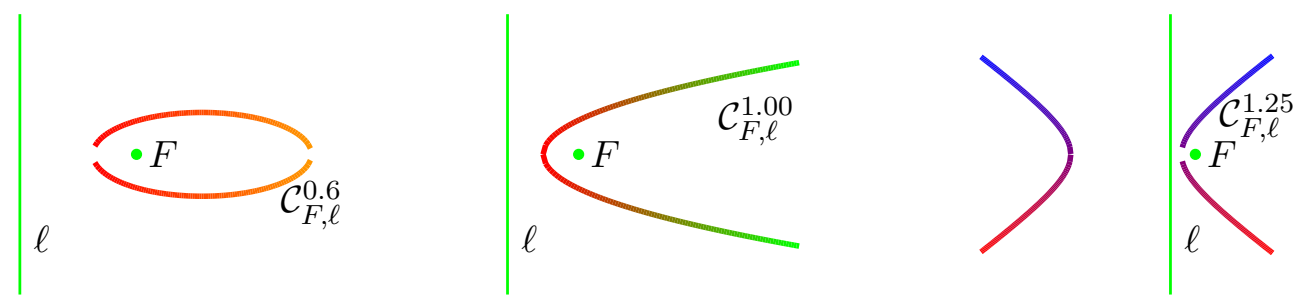

Every elliptic conical curve is a bounded closed curve contained in one side of the directrix. The elliptic conical curves are affine ellipses $\mathcal{Q}_{\mathfrak{s}}^{1}$, metric ellipses $\mathcal{E}_{F_{1}, F_{2}}^{a}$, and conic sections. Further, except the circles, every metric ellipse $\mathcal{E}_{F_{1}, F_{2}}^{a}$ is an elliptic conical curve.

Every parabolic conical curve is an unbounded curve contained in one side of the directrix. The parabolic conical curves are affine parabolas $\mathcal{Q}_{\mathfrak{s}}^{0}$, and conic sections. Further, every affine parabola $\mathcal{Q}_{\mathfrak{s}}^{0}$ is a parabolic conical curve.

Every hyperbolic conical curve has two separate unbounded connected curves, the branches, one-one on both sides of the directrix. The hyperbolic conical curves are affine hyperbolas $\mathcal{Q}_{\mathfrak{s}}^{-1}$, metric hyperbolas $\mathcal{H}_{F_{1}, F_{2}}^{a}$, and conic sections. Further, every affine hyperbola $\mathcal{Q}_{\mathfrak{s}}^{-1}$ is a hyperbolic conical curve. 


\section{Chapter 2}

\section{Conical curves with given properties}

In this chapter we consider conical curves in constant curvature planes. It turns out that some of their usual properties, like symmetry and quadraticity, remains valid only in very special configurations. We prove some of Kurusa's conjectures for curved constant curvature planes:

(1) no conical curve in the hyperbolic plane can be quadratic;

(2) no conical curve in the hyperbolic plane can be symmetric;

(3) if the focus of a conic curve on the sphere is not the pole of the directrix, then the conic can only be quadratic if it is a parabolic, and it can not be symmetric.

\subsection{Quadratic conical curves in the hyperbolic plane}

As for any pair $(F, \ell)$ of a point $F$ in $\mathcal{D}$ and an h-line $\ell$ there exists an isometry $\imath$ such that $\imath(\ell)$ goes through the center $O$ of $\mathcal{D}$, and $O$ is the foot of $\imath(F)$ on $\imath(\ell)$, we can restrict without loss of generality the investigation of conical curves to those conical curves $\mathcal{C}_{F, \ell}^{\varepsilon}$ in $(\mathcal{D}, \delta)$ for which the directrix $\ell$ is the $y$-axis, and the focus $F$ is $(f, 0)$, where $f \in(0,1)$.

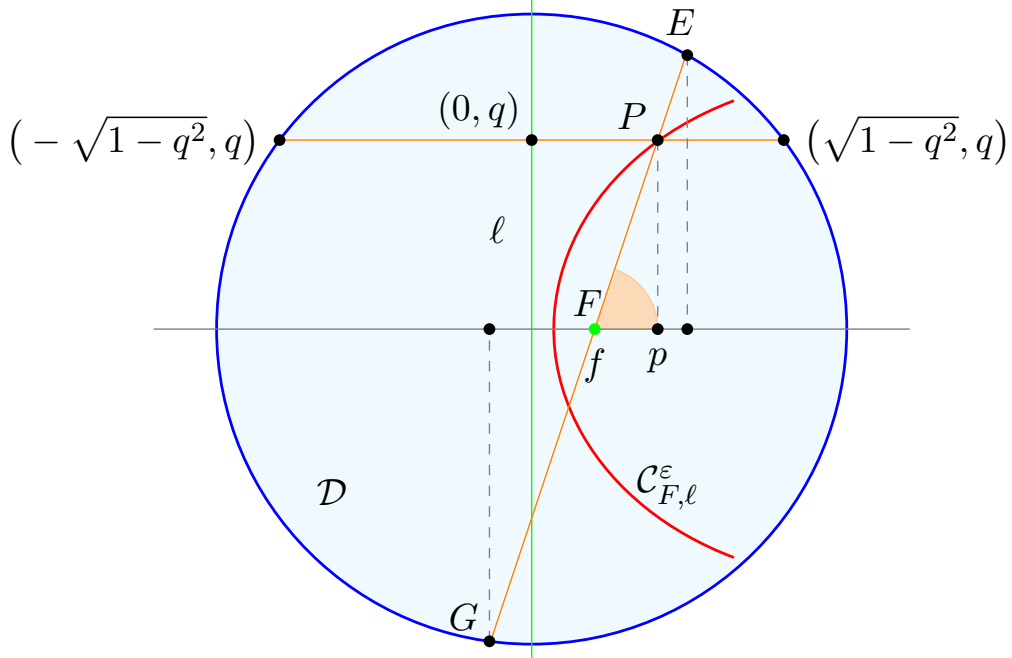

Figure 2.1: Directrix $\ell$ is through the center of the Cayley-Klein model, the focus $F$ is at $(f, 0)$, where $f \in(0,1)$. 
To calculate the points $P=(p, q)$ on $\mathcal{C}_{F, \ell}^{\varepsilon}$, we have to calculate $\delta(P, \ell)$ and $\delta(F, P)$, where $P=(p, q) \in \mathcal{C}_{F, \ell}^{\varepsilon}$. It is easy to get that

$$
\delta(P, \ell)=\frac{1}{2}\left|\log \left\{\frac{p+\sqrt{1-q^{2}}}{p-\sqrt{1-q^{2}}}: \frac{0+\sqrt{1-q^{2}}}{0-\sqrt{1-q^{2}}}\right\}\right| .
$$

To obtain $\delta(F, P)$, we firstly determine the points $\{E, G\}=\left\{\left(x_{ \pm}, y_{ \pm}\right)\right\}$, where line $F P$ intersects the unit circle, the border of $\mathcal{D}$. These points clearly satisfy the equations $x^{2}+y^{2}=1$ and $(x-f) q=y(p-f)$. So $(p-f)^{2}\left(1-x^{2}\right)=(x-f)^{2} q^{2}$, and we obtain $0=x^{2}\left((p-f)^{2}+q^{2}\right)-2 f q^{2} x+\left(f^{2} q^{2}-(p-f)^{2}\right)$, hence

$$
\begin{aligned}
& x_{ \pm}=\frac{f q^{2} \pm(p-f) \sqrt{(p-f)^{2}+\left(1-f^{2}\right) q^{2}}}{(p-f)^{2}+q^{2}} \\
& y_{ \pm}=\frac{-q f(p-f) \pm q \sqrt{(p-f)^{2}+\left(1-f^{2}\right) q^{2}}}{(p-f)^{2}+q^{2}} .
\end{aligned}
$$

Thus, we get

$$
\begin{aligned}
\delta(F, P) & =\frac{1}{2} \mid \log \left\{\frac{q^{2}+(p-f)^{2}+\left(f(p-f)+\sqrt{(p-f)^{2}+\left(1-f^{2}\right) q^{2}}\right)}{q^{2}+(p-f)^{2}+\left(f(p-f)-\sqrt{(p-f)^{2}+\left(1-f^{2}\right) q^{2}}\right)}\right. \\
\left.: \frac{f(p-f)+\sqrt{(p-f)^{2}+\left(1-f^{2}\right) q^{2}}}{f(p-f)-\sqrt{(p-f)^{2}+\left(1-f^{2}\right) q^{2}}}\right\} \mid & \\
= & \frac{1}{2}\left|\log \left\{\frac{\left(f p-1-\sqrt{(p-f)^{2}+\left(1-f^{2}\right) q^{2}}\right)^{2}}{\left(1-f^{2}\right)\left(1-p^{2}-q^{2}\right)}\right\}\right|,
\end{aligned}
$$

where we have used the identities

$$
\begin{aligned}
(f(p-f) & \left.+\sqrt{(p-f)^{2}+\left(1-f^{2}\right) q^{2}}\right)\left(f(p-f)-\sqrt{(p-f)^{2}+\left(1-f^{2}\right) q^{2}}\right) \\
& =f^{2}(p-f)^{2}-(p-f)^{2}-\left(1-f^{2}\right) q^{2}=-\left(1-f^{2}\right)\left(q^{2}+(p-f)^{2}\right),
\end{aligned}
$$

and

$$
\begin{aligned}
(f p-1 & \left.-\sqrt{(p-f)^{2}+\left(1-f^{2}\right) q^{2}}\right)\left(f p-1+\sqrt{(p-f)^{2}+\left(1-f^{2}\right) q^{2}}\right) \\
& =(f p-1)^{2}-(p-f)^{2}-\left(1-f^{2}\right) q^{2}=\left(1-f^{2}\right)\left(1-p^{2}-q^{2}\right) .
\end{aligned}
$$

According to $\left(D_{1}\right)$ equations (2.1) and (2.2) give

$$
\begin{aligned}
\left(1-q^{2}-p^{2}\right)(1 & \left.+\frac{2 p}{\sqrt{1-q^{2}}-p}\right)^{\epsilon} \\
& =\frac{\left(f p-1-\sqrt{q^{2}\left(1-f^{2}\right)+(p-f)^{2}}\right)^{2}}{1-f^{2}},
\end{aligned}
$$

where $\epsilon= \pm \varepsilon$. Figure 2.2 shows how these conical curves look like based on (2.3). 

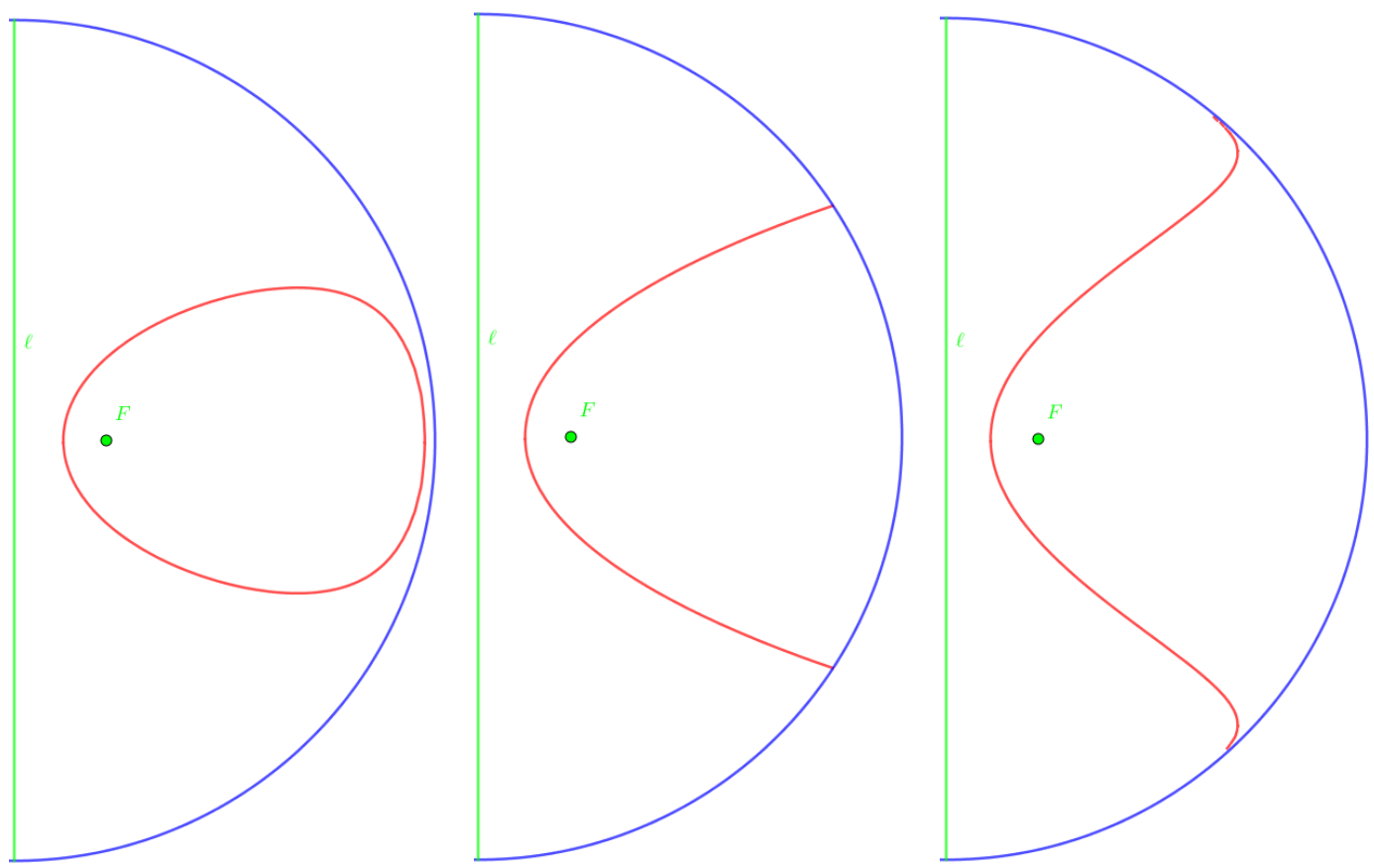

Figure 2.2: An elliptic $(\varepsilon=0.9)$, parabolic $(\varepsilon=1)$, and hyperbolic $(\varepsilon=1.1)$ conical curve in the Cayley-Klein model of the hyperbolic geometry.

For the sake of later contradiction, we assume from now on that

$$
\text { conical curve } \mathcal{C}_{F, \ell}^{\varepsilon} \text { is quadratic }\left(D_{q}\right) \text {, }
$$

hence it satisfies an equation of the form $\bar{a} x^{2}+\bar{b} x y+\bar{c} y^{2}+\bar{d} x+\bar{e} y+\bar{f}=0$, where the coefficients are real and $\bar{a} \geq 0$.

As the conical curves $\mathcal{C}_{F, \ell}^{\varepsilon}$ are symmetric in the $x$-axis, the quadratic equation should be invariant under changing $y$ to $-y$, so $\bar{b}=\bar{e}=0$ follows. So the equation is of the form $\bar{a} x^{2}+\bar{c} y^{2}+\bar{d} x+\bar{g}=0$, hence $\bar{c} \neq 0$, because otherwise the curve will degenerate into straight lines. So the quadratic equation simplifies to

$$
a x^{2}+y^{2}+b x+c=0, \quad a \geq 0 .
$$

As conical curve $\mathcal{C}_{F, \ell}^{\varepsilon}$ is quadratical, we have $q^{2}=-a p^{2}-b p-c, \quad a \geq 0$. Putting this into (2.3) gives the identity

$$
\begin{aligned}
\left(1-p^{2}+a p^{2}+b p+c\right)\left(1+\frac{2 p}{\sqrt{1+a p^{2}+b p+c}-p}\right)^{\varepsilon} \\
=\frac{\left(f p-1-\sqrt{-\left(a p^{2}+b p+c\right)\left(1-f^{2}\right)+(p-f)^{2}}\right)^{2}}{1-f^{2}} .
\end{aligned}
$$


Differentiating this with respect to $p$ gives

$$
\begin{aligned}
(-2 p+2 a p+b)\left(1+\frac{2 p}{\sqrt{1+a p^{2}+b p+c}-p}\right)^{\varepsilon}+ \\
+\varepsilon\left(1-p^{2}+a p^{2}+b p+c\right)\left(1+\frac{2 p}{\sqrt{1+a p^{2}+b p+c}-p}\right)^{\varepsilon-1} \times \\
\quad \times\left(\frac{2 p\left(\frac{2 a p+b}{2 \sqrt{1+a p^{2}+b p+c}}-1\right)}{\sqrt{1+a p^{2}+b p+c}-p}-\frac{2}{\left(\sqrt{1+a p^{2}+b p+c}-p\right)^{2}}\right) \\
=\frac{\left(f p-1-\sqrt{-\left(a p^{2}+b p+c\right)\left(1-f^{2}\right)+(p-f)^{2}}\right)}{1-f^{2}} \times \\
\times\left(2 f-\frac{-(2 a p+b)\left(1-f^{2}\right)+2(p-f)}{\sqrt{-\left(a p^{2}+b p+c\right)\left(1-f^{2}\right)+(p-f)^{2}}}\right) .
\end{aligned}
$$

The exponential multiplier in $(2.5)$ is

$$
\begin{aligned}
(1+ & \left.\frac{2 p}{\sqrt{1+a p^{2}+b p+c}-p}\right)^{\varepsilon} \\
& =\frac{\left(f p-1-\sqrt{-\left(a p^{2}+b p+c\right)\left(1-f^{2}\right)+(p-f)^{2}}\right)^{2}}{\left(1-f^{2}\right)\left(1-p^{2}+a p^{2}+b p+c\right)} .
\end{aligned}
$$

Putting this into (2.6) leads to

$$
\begin{aligned}
& (-2 p+2 a p+b) \frac{\left(f p-1-\sqrt{-\left(a p^{2}+b p+c\right)\left(1-f^{2}\right)+(p-f)^{2}}\right)^{2}}{\left(1-f^{2}\right)\left(1-p^{2}+a p^{2}+b p+c\right)}+ \\
& +\varepsilon \frac{\left(f p-1-\sqrt{-\left(a p^{2}+b p+c\right)\left(1-f^{2}\right)+(p-f)^{2}}\right)^{2}}{1-f^{2}} \times \\
& \times\left(1+\frac{2 p}{\sqrt{1+a p^{2}+b p+c}-p}\right)^{-1} \times \\
& \times\left(\frac{2}{\sqrt{1+a p^{2}+b p+c}-p}-\frac{2 p\left(\frac{2 a p+b}{2 \sqrt{1+a p^{2}+b p+c}}-1\right)}{\left(\sqrt{1+a p^{2}+b p+c}-p\right)^{2}}\right) \\
& =\frac{\left(f p-1-\sqrt{-\left(a p^{2}+b p+c\right)\left(1-f^{2}\right)+(p-f)^{2}}\right)}{1-f^{2}} \times \\
& \times\left(2 f-\frac{-(2 a p+b)\left(1-f^{2}\right)+2(p-f)}{\sqrt{-\left(a p^{2}+b p+c\right)\left(1-f^{2}\right)+(p-f)^{2}}}\right) .
\end{aligned}
$$

This simplifies to

$$
\begin{aligned}
(-2 p+2 a p & +b) \frac{\left(f p-1-\sqrt{-\left(a p^{2}+b p+c\right)\left(1-f^{2}\right)+(p-f)^{2}}\right)^{2}}{\left(1-f^{2}\right)\left(1-p^{2}+a p^{2}+b p+c\right)}+ \\
& +\varepsilon \frac{\left(f p-1-\sqrt{-\left(a p^{2}+b p+c\right)\left(1-f^{2}\right)+(p-f)^{2}}\right)^{2}}{\left(1-f^{2}\right)\left(\sqrt{1+a p^{2}+b p+c}+p\right)} \times \\
& \times\left(2-\frac{2 p\left(\frac{2 a p+b}{2 \sqrt{1+a p^{2}+b p+c}}-1\right)}{\sqrt{1+a p^{2}+b p+c}-p}\right)
\end{aligned}
$$

Ahmed Mohsin Mahdi: Conical Curves in Constant Curvature Planes 


$$
\begin{gathered}
=\frac{\left(f p-1-\sqrt{-\left(a p^{2}+b p+c\right)\left(1-f^{2}\right)+(p-f)^{2}}\right)}{1-f^{2}} \times \\
\times\left(2 f-\frac{-(2 a p+b)\left(1-f^{2}\right)+2(p-f)}{\sqrt{-\left(a p^{2}+b p+c\right)\left(1-f^{2}\right)+(p-f)^{2}}}\right) .
\end{gathered}
$$

Dividing by $\frac{\left(f p-1-\sqrt{-\left(a p^{2}+b p+c\right)\left(1-f^{2}\right)+(p-f)^{2}}\right)}{\left(1-f^{2}\right)\left(1-p^{2}+a p^{2}+b p+c\right)}$ further simplifies the equation to

$$
\begin{aligned}
((-2 p & \left.+2 a p+b)+\varepsilon\left(\sqrt{1+a p^{2}+b p+c}-p\right)\left(2-\frac{2 p\left(\frac{2 a p+b}{2 \sqrt{1+a p^{2}+b p+c}}-1\right)}{\sqrt{1+a p^{2}+b p+c}-p}\right)\right) \times \\
& \times\left(f p-1-\sqrt{-\left(a p^{2}+b p+c\right)\left(1-f^{2}\right)+(p-f)^{2}}\right) \\
= & \left(1-p^{2}+a p^{2}+b p+c\right)\left(2 f-\frac{-(2 a p+b)\left(1-f^{2}\right)+2(p-f)}{\sqrt{-\left(a p^{2}+b p+c\right)\left(1-f^{2}\right)+(p-f)^{2}}}\right)
\end{aligned}
$$

i.e.

$$
\begin{aligned}
& \left((-2 p+2 a p+b)+\varepsilon\left(\sqrt{1+a p^{2}+b p+c}-p\right)\left(2-\frac{2 p\left(\frac{2 a p+b}{2 \sqrt{1+a p^{2}+b p+c}}-1\right)}{\sqrt{1+a p^{2}+b p+c}-p}\right)\right) \times \\
& \quad \times\left((f p-1) \sqrt{-\left(a p^{2}+b p+c\right)\left(1-f^{2}\right)+(p-f)^{2}}+\right. \\
& \left.\quad+\left(a p^{2}+b p+c\right)\left(1-f^{2}\right)-(p-f)^{2}\right) \\
& =\left(1-p^{2}+a p^{2}+b p+c\right) \times \\
& \quad \times\left(2 f \sqrt{-\left(a p^{2}+b p+c\right)\left(1-f^{2}\right)+(p-f)^{2}}+(2 a p+b)\left(1-f^{2}\right)-2(p-f)\right) .
\end{aligned}
$$

With some rearrangement we obtain

$$
\begin{aligned}
& 2 \varepsilon\left(\sqrt{1+a p^{2}+b p+c}-\frac{p(2 a p+b)}{2 \sqrt{1+a p^{2}+b p+c}}\right) \times \\
& \quad \times\left((f p-1) \sqrt{-\left(a p^{2}+b p+c\right)\left(1-f^{2}\right)+(p-f)^{2}}+\right. \\
& \left.\quad+\left(a p^{2}+b p+c\right)\left(1-f^{2}\right)-(p-f)^{2}\right) \\
& =\left(1-p^{2}+a p^{2}+b p+c\right) \times \\
& \quad \times\left(2 f \sqrt{-\left(a p^{2}+b p+c\right)\left(1-f^{2}\right)+(p-f)^{2}}+(2 a p+b)\left(1-f^{2}\right)-2(p-f)\right)- \\
& -(-2 p+2 a p+b) \times \quad \\
& \quad \times\left((f p-1) \sqrt{-\left(a p^{2}+b p+c\right)\left(1-f^{2}\right)+(p-f)^{2}}+\right. \\
& \left.\quad+\left(a p^{2}+b p+c\right)\left(1-f^{2}\right)-(p-f)^{2}\right),
\end{aligned}
$$


and again some rearrangement gives

$$
\begin{aligned}
2 \varepsilon( & \left.\sqrt{1+a p^{2}+b p+c}-\frac{p(2 a p+b)}{2 \sqrt{1+a p^{2}+b p+c}}\right) \times \\
\times & \left((f p-1) \sqrt{-\left(a p^{2}+b p+c\right)\left(1-f^{2}\right)+(p-f)^{2}}+\right. \\
& \left.+\left(a p^{2}+b p+c\right)\left(1-f^{2}\right)-(p-f)^{2}\right) \\
= & \left(2 f\left(1-p^{2}+a p^{2}+b p+c\right)-(-2 p+2 a p+b)(f p-1)\right) \times \\
& \times \sqrt{-\left(a p^{2}+b p+c\right)\left(1-f^{2}\right)+(p-f)^{2}}+ \\
+ & \left(\left(1-p^{2}+a p^{2}+b p+c\right)\left((2 a p+b)\left(1-f^{2}\right)-2(p-f)\right)-\right. \\
& \left.-(-2 p+2 a p+b)\left(\left(a p^{2}+b p+c\right)\left(1-f^{2}\right)-(p-f)^{2}\right)\right),
\end{aligned}
$$

then

$$
\begin{aligned}
& \varepsilon(2(1+c)+p b) \\
& =\sqrt{1+a p^{2}+b p+c} \times \\
& \quad \times\left(((f b+2 a-2) p+2 f+2 f c+b) \sqrt{-\left(a p^{2}+b p+c\right)\left(1-f^{2}\right)+(p-f)^{2}}+\right. \\
& \left.\quad+f(2-b f-2 a) p^{2}+2\left(a-1+f^{2}(c+1)\right) p+b+2 f(c+1)\right),
\end{aligned}
$$

so we arrive at

$$
\begin{aligned}
& \varepsilon(2(1+c)+p b) \\
&=((f b+2 a-2) p+2 f(c+1)+b) \times \\
& \quad \times \sqrt{\left((p-f)^{2}-\left(a p^{2}+b p+c\right)\left(1-f^{2}\right)\right)\left(1+a p^{2}+b p+c\right)}+ \\
&+\left(f(2-b f-2 a) p^{2}+2\left(a-1+f^{2}(c+1)\right) p+2 f(c+1)+b\right) \times \\
& \quad \times \sqrt{1+a p^{2}+b p+c .}
\end{aligned}
$$

Squaring this gives

$$
\begin{aligned}
& \varepsilon^{2}(2(1+c)+p b)^{2}- \\
& -\left(((f b+2 a-2) p+2 f(c+1)+b)^{2}\left((p-f)^{2}-\left(a p^{2}+b p+c\right)\left(1-f^{2}\right)\right)+\right. \\
& \left.\quad+\left(f(2-b f-2 a) p^{2}+2\left(a-1+f^{2}(c+1)\right) p+2 f(c+1)+b\right)^{2}\right) \times \\
& \quad \times\left(1+a p^{2}+b p+c\right) \\
& =2((f b+2 a-2) p+2 f(c+1)+b)\left(1+a p^{2}+b p+c\right) \times \\
& \quad \times\left(f(2-b f-2 a) p^{2}+2\left(a-1+f^{2}(c+1)\right) p+2 f(c+1)+b\right) \times \\
& \quad \times \sqrt{(p-f)^{2}-\left(a p^{2}+b p+c\right)\left(1-f^{2}\right)} .
\end{aligned}
$$


Squaring again gives the identity of two polynomials

$$
\begin{aligned}
& \varepsilon^{4}(2(1+c)+p b)^{4}+ \\
&+\left(((f b+2 a-2) p+2 f(c+1)+b)^{2}\left((p-f)^{2}-\left(a p^{2}+b p+c\right)\left(1-f^{2}\right)\right)+\right. \\
&\left.\quad+\left(f(2-b f-2 a) p^{2}+2\left(a-1+f^{2}(c+1)\right) p+2 f(c+1)+b\right)^{2}\right)^{2} \times \\
& \times\left(1+a p^{2}+b p+c\right)^{2}+ \\
&+ 2 \varepsilon^{2}(2(1+c)+p b)^{2} \times \\
& \quad \times\left(((f b+2 a-2) p+2 f(c+1)+b)^{2}\left((p-f)^{2}-\left(a p^{2}+b p+c\right)\left(1-f^{2}\right)\right)+\right. \\
&\left.\quad+\left(f(2-b f-2 a) p^{2}+2\left(a-1+f^{2}(c+1)\right) p+2 f(c+1)+b\right)^{2}\right) \times \\
& \quad \times\left(1+a p^{2}+b p+c\right) \\
&=4(f b+2 a-2) p+2 f(c+1)+b)^{2}\left(1+a p^{2}+b p+c\right)^{2} \times \\
& \quad\left(f(2-b f-2 a) p^{2}+2\left(a-1+f^{2}(c+1)\right) p+2 f(c+1)+b\right)^{2} \times \\
& \times\left((p-f)^{2}-\left(a p^{2}+b p+c\right)\left(1-f^{2}\right)\right) .
\end{aligned}
$$

Two polynomials can only be equal on a segment, if their corresponding coefficients are pairwise equal. The coefficients of $p^{12}$ are equal, so

$$
\begin{aligned}
\left((f b+2 a-2)^{2}\right. & \left.\left(1-a\left(1-f^{2}\right)\right)+f^{2}(2-b f-2 a)^{2}\right)^{2} a^{2} \\
& =4(f b+2 a-2)^{2} a^{2} f^{2}(2-b f-2 a)^{2}\left(1-a\left(1-f^{2}\right)\right)
\end{aligned}
$$

that is equivalent to

$$
a^{2}(f b+2 a-2)^{4}\left(\left(\left(1-a\left(1-f^{2}\right)\right)+f^{2}\right)^{2}-4 f^{2}\left(1-a\left(1-f^{2}\right)\right)\right)=0,
$$

so either $a=0$, which is disclosed by $a>0$, or $1-a\left(1-f^{2}\right)=f^{2}$, i.e. $a=1$, that implies $b=0$ in (2.8), or $f b+2 a-2=0$.

Assuming $f b+2 a-2=0$ simplifies (2.7) into

$$
\begin{aligned}
\varepsilon^{4}(2(1+c)+p b)^{4}+ \\
+\quad\left((2 f(c+1)+b)^{2}\left((p-f)^{2}-\left(a p^{2}+b p+c\right)\left(1-f^{2}\right)\right)+\right. \\
\left.\quad+\left(2\left(a-1+f^{2}(c+1)\right) p+2 f(c+1)+b\right)^{2}\right)^{2}\left(1+a p^{2}+b p+c\right)^{2}+ \\
+2 \varepsilon^{2}(2(1+c)+p b)^{2} \times \\
\quad \times\left((2 f(c+1)+b)^{2}\left((p-f)^{2}-\left(a p^{2}+b p+c\right)\left(1-f^{2}\right)\right)+\right. \\
\left.\quad+\left(2\left(a-1+f^{2}(c+1)\right) p+2 f(c+1)+b\right)^{2}\right)\left(1+a p^{2}+b p+c\right) \\
=4(2 f(c+1)+b)^{2}\left(1+a p^{2}+b p+c\right)^{2} \times \\
\quad \times\left(2\left(a-1+f^{2}(c+1)\right) p+2 f(c+1)+b\right)^{2} \times \\
\quad \times\left((p-f)^{2}-\left(a p^{2}+b p+c\right)\left(1-f^{2}\right)\right) .
\end{aligned}
$$


Two polynomials can only be equal on a segment, if their corresponding coefficients are pairwise equal. The coefficients of $p^{8}$ are equal, so

$$
\begin{aligned}
& \left((2 f(c+1)+b)^{2}\left(1-a\left(1-f^{2}\right)\right)+4\left(a-1+f^{2}(c+1)\right)^{2}\right)^{2} a^{2} \\
& \quad=4(2 f(c+1)+b)^{2} a^{2} 4\left(a-1+f^{2}(c+1)\right)^{2}\left(1-a\left(1-f^{2}\right)\right)
\end{aligned}
$$

that is equivalent to

$$
a^{2}\left((2 f(c+1)+b)^{2}\left(1-a\left(1-f^{2}\right)\right)-4\left(a-1+f^{2}(c+1)\right)^{2}\right)^{2}=0,
$$

so either $a=0$, which is disclosed by $a>0$, or $(2 f(c+1)+b)^{2}\left(1-a\left(1-f^{2}\right)\right)=$ $4\left(a-1+f^{2}(c+1)\right)^{2}$. Thus, $\left(2 f^{2}(c+1)+f b\right)^{2}\left(1-a\left(1-f^{2}\right)\right)=4 f^{2}\left(a-1+f^{2}(c+1)\right)^{2}$, hence $\left(f^{2}(c+1)+1-a\right)^{2}\left(1-a\left(1-f^{2}\right)\right)=f^{2}\left(a-1+f^{2}(c+1)\right)^{2}$, and therefore $1-a\left(1-f^{2}\right) \geq 0$, i.e., $a<1 /\left(1-f^{2}\right)$. Assuming $f^{2}(c+1)+(1-a) \neq 0$, we can write this equation in the form

$$
\frac{\left(f^{2}(c+1)-(1-a)\right)^{2}}{\left(f^{2}(c+1)+(1-a)\right)^{2}}=\frac{a f^{2}+1-a}{f^{2}},
$$

which, if $c+1 \neq 0$, leads to

$$
\begin{array}{ll}
1>\frac{\left(f^{2}(c+1)-(1-a)\right)^{2}}{\left(f^{2}(c+1)+(1-a)\right)^{2}}=\frac{a f^{2}+1-a}{f^{2}}>1 & \text { if } a \in(0,1), \\
1<\frac{\left(f^{2}(c+1)-(1-a)\right)^{2}}{\left(f^{2}(c+1)+(1-a)\right)^{2}}=\frac{a f^{2}+1-a}{f^{2}}<1 & \text { if } a \in\left(1,1 /\left(1-f^{2}\right)\right),
\end{array}
$$

a clear contradiction. Thus, $c=-1$, and consequently $a=1$. If $f^{2}(c+1)+(1-a)=0$, then also $f^{2}(c+1)-(1-a)=0$, so $a=1$.

Thus, in any case, we obtained $a=1$. This simplifies (2.7) into

$$
\begin{aligned}
& \varepsilon^{4}(2(1+c)+p b)^{4}+ \\
&+\left((f b p+2 f(c+1)+b)^{2}\left(f^{2}-p\left(2 f+b\left(1-f^{2}\right)\right)-c\left(1-f^{2}\right)\right)+\right. \\
&\left.\quad+\left(-b f^{2} p^{2}+2 f^{2}(c+1) p+2 f(c+1)+b\right)^{2}\right)^{2} \times \\
& \times\left(1+p^{2}+b p+c\right)^{2}+ \\
&+ 2 \varepsilon^{2}(2(1+c)+p b)^{2} \times \\
& \quad\left((f b p+2 f(c+1)+b)^{2}\left(f^{2}-p\left(2 f+b\left(1-f^{2}\right)\right)-c\left(1-f^{2}\right)\right)+\right. \\
&\left.\quad+\left(-b f^{2} p^{2}+2 f^{2}(c+1) p+2 f(c+1)+b\right)^{2}\right) \times \\
& \times\left(1+p^{2}+b p+c\right) \\
&=4f b p+2 f(c+1)+b)^{2}\left(1+p^{2}+b p+c\right)^{2} \times \\
& \quad \times\left(-b f^{2} p^{2}+2 f^{2}(c+1) p+2 f(c+1)+b\right)^{2} \times \\
& \times\left(f^{2}-p\left(2 f+b\left(1-f^{2}\right)\right)-c\left(1-f^{2}\right)\right) .
\end{aligned}
$$


Two polynomials can only be equal on a segment, if their corresponding coefficients are pairwise equal. The coefficients of $p^{12}$ are equal, so $b^{4} f^{8}=0$, hence $b=0$.

Thus, in any case, we obtained $a=1$ and $b=0$. This simplifies (2.11) into

$$
\begin{aligned}
& \varepsilon^{4} 16(1+c)^{4}+ \\
& +(2 f(c+1))^{4}\left(\left(f^{2}-2 f p-c\left(1-f^{2}\right)\right)+(f p+1)^{2}\right)^{2}\left(1+p^{2}+c\right)^{2}+ \\
& +2 \varepsilon^{2} 4(1+c)^{2}(2 f(c+1))^{2} \times \\
& \quad \times\left(\left(f^{2}-2 f p-c\left(1-f^{2}\right)\right)+(f(c+1) p+1)^{2}\right)\left(1+p^{2}+c\right) \\
& =4(2 f(c+1))^{4}\left(1+p^{2}+c\right)^{2}(f p+1)^{2}\left(f^{2}-2 f p-c\left(1-f^{2}\right)\right) .
\end{aligned}
$$

Two polynomials can only be equal on a segment, if their corresponding coefficients are pairwise equal. The coefficients of $p^{8}$ are equal, so $(2 f(c+1))^{4}\left(5 f^{2}\right)^{2}=0$, hence $c=-1$.

Thus, by (2.4), if the conical curve $\mathcal{C}_{F, \ell}^{\varepsilon}$ is quadratic, then it is of the form $x^{2}+y^{2}=1$, a clear contradiction that proves the following:

Theorem 2.1 ([11]). No conical curve of the hyperbolic plane can be quadratic.

\subsection{Symmetric conical curves in the hyperbolic plane}

Consider a conical curve $\mathcal{C}_{F, \ell}^{\varepsilon}$. Let $F^{\perp}$ be the foot of $F$ on the h-line $\ell$, and let $C$ be a point on the h-line $F F^{\perp}$ different from $F^{\perp}$.

It is well known that there are h-isometries that maps $C$ into the center $O$ of $\mathcal{D}$. Thus we can restrict without loss of generality the investigation of conical curves $\mathcal{C}_{F, \ell}^{\varepsilon}$ in $(\mathcal{D}, \delta)$ to those ones for which $\overline{\left(m,-\sqrt{1-m^{2}}\right)\left(m, \sqrt{1-m^{2}}\right)}$ is the directrix $\ell$ for some $m \in(-1,0)$, the center is $O=(0,0)$, and the focus $F$ is $(f, 0)$, where $f \in(-1,1) \backslash\{m\}$.

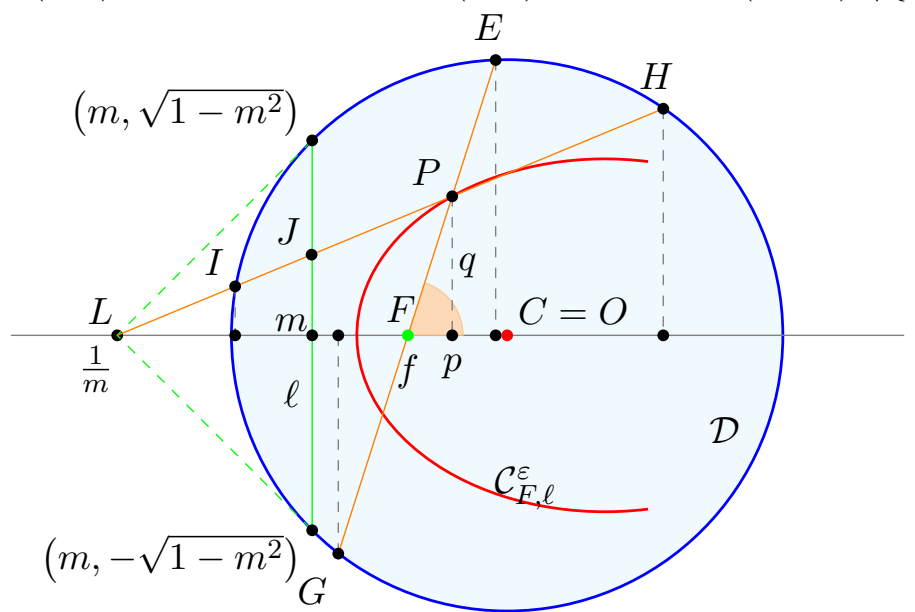

Figure 2.3: Directrix $\ell$ is $\overline{\left(m,-\sqrt{1-m^{2}}\right)\left(m, \sqrt{1-m^{2}}\right)}, \mathcal{C}_{F, \ell}^{\varepsilon}$ is symmetric in $O$, the center of the Cayley-Klein model, and the focus $F$ is at $(f, 0)$, where $f \in(-1,1) \backslash\{m\}$. 
To calculate the points $P=(p, q)$ on $\mathcal{C}_{F, \ell}^{\varepsilon}$, we have to calculate $\delta(P, \ell)$ and $\delta(F, P)$, where $P=(p, q) \in \mathcal{C}_{F, \ell}^{\varepsilon}$. Observe that the line through $P$ orthogonal to $\ell$ is the one that connects $P$ to $L$, the intersection of the tangents of $\mathcal{D}$ at the limit points of $\ell$. We clearly have $L=(-1 / m, 0)$.

To obtain $\delta(P, \ell)$, we firstly determine the points $\{I, H\}=\left\{\left(x_{ \pm}, y_{ \pm}\right)\right\}$, where line $L P$ intersects the unit circle, the border of $\mathcal{D}$. These points clearly satisfy the equations $x^{2}+y^{2}=1$ and $(x-1 / m) q=y(p-1 / m)$. So $(p-1 / m)^{2}\left(1-x^{2}\right)=(x-1 / m)^{2} q^{2}$, and we obtain $0=x^{2}\left(\left(p-\frac{1}{m}\right)^{2}+q^{2}\right)-2 \frac{q^{2}}{m} x+\left(\frac{q^{2}}{m^{2}}-\left(p-\frac{1}{m}\right)^{2}\right)$, hence

$$
x_{ \pm}=\frac{\frac{q^{2}}{m} \pm\left(p-\frac{1}{m}\right) \sqrt{\left(p-\frac{1}{m}\right)^{2}+q^{2} \frac{1-m^{2}}{m^{2}}}}{\left(p-\frac{1}{m}\right)^{2}+q^{2}}, \quad y_{ \pm}=\frac{-\frac{q}{m}\left(p-\frac{1}{m}\right) \pm q \sqrt{\left(p-\frac{1}{m}\right)^{2}+q^{2} \frac{1-m^{2}}{m^{2}}}}{\left(p-\frac{1}{m}\right)^{2}+q^{2}}
$$

Further, we need the coordinates of point $J$, where $P L$ intersects $\ell$. We clearly have $(m-1 / m) q=y(p-1 / m)$, hence $y=q\left(m-\frac{1}{m}\right) /\left(p-\frac{1}{m}\right)$. Thus

$$
\begin{aligned}
& \delta(P, \ell)=\delta(P, J) \\
& =\frac{1}{2} \mid \log \left\{\frac{\left(\left(p-\frac{1}{m}\right)^{2}+q^{2}\right)+\frac{1}{m}\left(p-\frac{1}{m}\right)+\sqrt{\left(p-\frac{1}{m}\right)^{2}+q^{2} \frac{1-m^{2}}{m^{2}}}}{\left(\left(p-\frac{1}{m}\right)^{2}+q^{2}\right)+\frac{1}{m}\left(p-\frac{1}{m}\right)-\sqrt{\left(p-\frac{1}{m}\right)^{2}+q^{2} \frac{1-m^{2}}{m^{2}}}}\right. \\
& \left.: \frac{\frac{m-\frac{1}{m}}{p-\frac{1}{m}}\left(\left(p-\frac{1}{m}\right)^{2}+q^{2}\right)+\frac{1}{m}\left(p-\frac{1}{m}\right)+\sqrt{\left(p-\frac{1}{m}\right)^{2}+q^{2} \frac{1-m^{2}}{m^{2}}}}{\frac{m-\frac{1}{m}}{p-\frac{1}{m}}\left(\left(p-\frac{1}{m}\right)^{2}+q^{2}\right)+\frac{1}{m}\left(p-\frac{1}{m}\right)-\sqrt{\left(p-\frac{1}{m}\right)^{2}+q^{2} \frac{1-m^{2}}{m^{2}}}}\right\} \mid .
\end{aligned}
$$

So

$$
\begin{aligned}
& \delta(P, \ell) \\
& =\frac{1}{2} \mid \log \left\{\frac{\left(\left(p-\frac{1}{m}\right)^{2}+q^{2}\right)+\left(\sqrt{\left(p-\frac{1}{m}\right)^{2}+q^{2}\left(1-\frac{1}{m^{2}}\right)}+\frac{1}{m}\left(p-\frac{1}{m}\right)\right)}{\left(\left(p-\frac{1}{m}\right)^{2}+q^{2}\right)-\left(\sqrt{\left(p-\frac{1}{m}\right)^{2}+q^{2}\left(1-\frac{1}{m^{2}}\right)}-\frac{1}{m}\left(p-\frac{1}{m}\right)\right)}\right. \\
& \left.: \frac{m\left(p-\frac{1}{m}\right)+\frac{m-\frac{1}{m}}{p-\frac{1}{m}} q^{2}+\sqrt{\left(p-\frac{1}{m}\right)^{2}+q^{2}\left(1-\frac{1}{m^{2}}\right)}}{m\left(p-\frac{1}{m}\right)+\frac{m-\frac{1}{m}}{p-\frac{1}{m}} q^{2}-\sqrt{\left(p-\frac{1}{m}\right)^{2}+q^{2}\left(1-\frac{1}{m^{2}}\right)}}\right\} \mid \\
& =\frac{1}{2} \mid \log \left\{\frac{\left(\left(p-\frac{1}{m}\right)^{2}+q^{2}\right)+\left(\sqrt{\left(p-\frac{1}{m}\right)^{2}+q^{2}\left(1-\frac{1}{m^{2}}\right)}+\frac{1}{m}\left(p-\frac{1}{m}\right)\right)}{\left(\left(p-\frac{1}{m}\right)^{2}+q^{2}\right)-\left(\sqrt{\left(p-\frac{1}{m}\right)^{2}+q^{2}\left(1-\frac{1}{m^{2}}\right)}-\frac{1}{m}\left(p-\frac{1}{m}\right)\right.} \times\right. \\
& \left.\times \frac{\left(p-\frac{1}{m}\right)^{2}+\left(1-\frac{1}{m^{2}}\right) q^{2}-\frac{1}{m}\left(p-\frac{1}{m}\right) \sqrt{\left(p-\frac{1}{m}\right)^{2}+q^{2}\left(1-\frac{1}{m^{2}}\right)}}{\left(p-\frac{1}{m}\right)^{2}+\left(1-\frac{1}{m^{2}}\right) q^{2}+\frac{1}{m}\left(p-\frac{1}{m}\right) \sqrt{\left(p-\frac{1}{m}\right)^{2}+q^{2}\left(1-\frac{1}{m^{2}}\right)}}\right\} \mid \\
& =\frac{1}{2} \mid \log \left\{\frac{\left(\left(p-\frac{1}{m}\right)^{2}+q^{2}\right)+\left(\sqrt{\left(p-\frac{1}{m}\right)^{2}+q^{2}\left(1-\frac{1}{m^{2}}\right)}+\frac{1}{m}\left(p-\frac{1}{m}\right)\right)}{\left(\left(p-\frac{1}{m}\right)^{2}+q^{2}\right)-\left(\sqrt{\left(p-\frac{1}{m}\right)^{2}+q^{2}\left(1-\frac{1}{m^{2}}\right)}-\frac{1}{m}\left(p-\frac{1}{m}\right)\right)} \times\right.
\end{aligned}
$$




$$
\begin{gathered}
\left.\quad \times \frac{\sqrt{\left(p-\frac{1}{m}\right)^{2}+q^{2}\left(1-\frac{1}{m^{2}}\right)}-\frac{1}{m}\left(p-\frac{1}{m}\right)}{\sqrt{\left(p-\frac{1}{m}\right)^{2}+q^{2}\left(1-\frac{1}{m^{2}}\right)}+\frac{1}{m}\left(p-\frac{1}{m}\right)}\right\} \mid \\
=\frac{1}{2} \mid \log \left\{\frac{\left(\left(p-\frac{1}{m}\right)^{2}+q^{2}\right) \sqrt{\left(p-\frac{1}{m}\right)^{2}+q^{2}\left(1-\frac{1}{m^{2}}\right)}+\left(\left(p-\frac{1}{m}\right)^{2}+q^{2}\right)\left(1-\frac{1}{m} p\right)}{\left(\left(p-\frac{1}{m}\right)^{2}+q^{2}\right) \sqrt{\left(p-\frac{1}{m}\right)^{2}+q^{2}\left(1-\frac{1}{m^{2}}\right)}-\left(\left(p-\frac{1}{m}\right)^{2}+q^{2}\right)\left(1-\frac{1}{m} p\right)}\right\} \\
=\frac{1}{2}\left|\log \left\{\frac{\sqrt{\left(p-\frac{1}{m}\right)^{2}+q^{2}\left(1-\frac{1}{m^{2}}\right)}+\left(1-\frac{1}{m} p\right)}{\sqrt{\left(p-\frac{1}{m}\right)^{2}+q^{2}\left(1-\frac{1}{m^{2}}\right)}-\left(1-\frac{1}{m} p\right)}\right\}\right| \\
=\frac{1}{2}\left|\log \left\{\frac{\left(\sqrt{\left(p-\frac{1}{m}\right)^{2}+q^{2}\left(1-\frac{1}{m^{2}}\right)}+\left(1-\frac{1}{m} p\right)\right)^{2}}{\left(1-p^{2}-q^{2}\right)\left(\frac{1}{m^{2}}-1\right)}\right\}\right| .
\end{gathered}
$$

To obtain $\delta(F, P)$, we firstly determine the points $E=\left(x_{1}, y_{1}\right)$ and $G=\left(x_{2}, y_{2}\right)$, where line FP intersects the unit circle, the border of $\mathcal{D}$. These points clearly satisfy the equations $x^{2}+y^{2}=1$ and $(x-f) q=y(p-f)$. So $(p-f)^{2}\left(1-x^{2}\right)=(x-f)^{2} q^{2}$, and we obtain $0=x^{2}\left((p-f)^{2}+q^{2}\right)-2 f q^{2} x+\left(f^{2} q^{2}-(p-f)^{2}\right)$, hence

$$
x_{ \pm}=\frac{f q^{2} \pm(p-f) \sqrt{(p-f)^{2}+\left(1-f^{2}\right) q^{2}}}{(p-f)^{2}+q^{2}}, y_{ \pm}=\frac{-q f(p-f) \pm q \sqrt{(p-f)^{2}+\left(1-f^{2}\right) q^{2}}}{(p-f)^{2}+q^{2}} .
$$

Thus, we get

$$
\begin{aligned}
& \delta(F, P)= \frac{1}{2} \mid \log \left\{\frac{q^{2}+(p-f)^{2}+\left(f(p-f)+\sqrt{(p-f)^{2}+\left(1-f^{2}\right) q^{2}}\right)}{q^{2}+(p-f)^{2}+\left(f(p-f)-\sqrt{(p-f)^{2}+\left(1-f^{2}\right) q^{2}}\right)}\right. \\
&\left.: \frac{f(p-f)+\sqrt{(p-f)^{2}+\left(1-f^{2}\right) q^{2}}}{f(p-f)-\sqrt{(p-f)^{2}+\left(1-f^{2}\right) q^{2}}}\right\} \mid \\
&=\frac{1}{2}\left|\log \left\{\frac{\left(f p-1-\sqrt{(p-f)^{2}+\left(1-f^{2}\right) q^{2}}\right)^{2}}{\left(1-f^{2}\right)\left(1-p^{2}-q^{2}\right)}\right\}\right|,
\end{aligned}
$$

where we have used the identities

$$
\begin{aligned}
(f(p-f) & \left.+\sqrt{(p-f)^{2}+\left(1-f^{2}\right) q^{2}}\right)\left(f(p-f)-\sqrt{(p-f)^{2}+\left(1-f^{2}\right) q^{2}}\right) \\
& =f^{2}(p-f)^{2}-(p-f)^{2}-\left(1-f^{2}\right) q^{2}=-\left(1-f^{2}\right)\left(q^{2}+(p-f)^{2}\right) \\
(f p-1 & \left.-\sqrt{(p-f)^{2}+\left(1-f^{2}\right) q^{2}}\right)\left(f p-1+\sqrt{(p-f)^{2}+\left(1-f^{2}\right) q^{2}}\right) \text { inthissection } \\
& =(f p-1)^{2}-(p-f)^{2}-\left(1-f^{2}\right) q^{2}=\left(1-f^{2}\right)\left(1-p^{2}-q^{2}\right) .
\end{aligned}
$$

According to $\left(D_{1}\right)$ equations $(2.13)$ and (2.14) give

$$
\left(\frac{\left(\sqrt{\left(p-\frac{1}{m}\right)^{2}+q^{2}\left(1-\frac{1}{m^{2}}\right)}+\left(1-\frac{1}{m} p\right)\right)^{2}}{\left(1-p^{2}-q^{2}\right)\left(\frac{1}{m^{2}}-1\right)}\right)^{\epsilon}=\frac{\left(f p-1-\sqrt{q^{2}\left(1-f^{2}\right)+(p-f)^{2}}\right)^{2}}{\left(1-f^{2}\right)\left(1-q^{2}-p^{2}\right)}
$$


where $\epsilon \in\{\varepsilon,-\varepsilon\}$. Figure 2.2 shows how these conical curves look like based on (2.15) with $\epsilon=\varepsilon$.

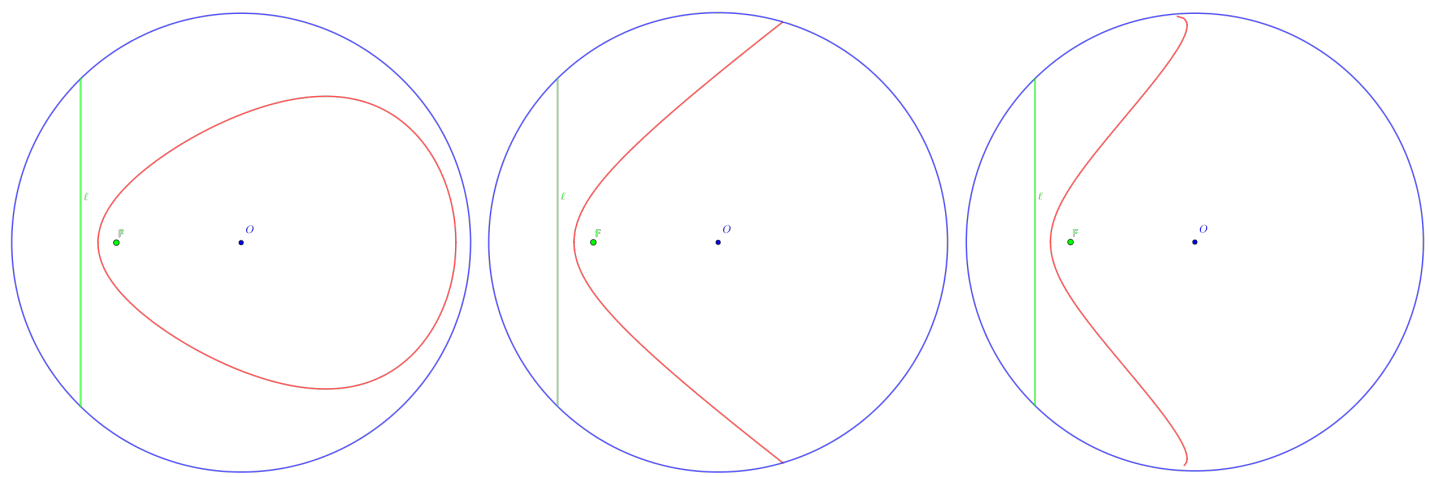

Figure 2.4: An elliptic $(\varepsilon=0.9)$, parabolic $(\varepsilon=1)$, and hyperbolic $(\varepsilon=1.1)$ conical curve in the Cayley-Klein model of the hyperbolic geometry.

For the sake of later contradiction, we assume from now on that

conical curve $\mathcal{C}_{F, \ell}^{\varepsilon}$ is symmetric in a point $C$.

Such a point of symmetry $C$ clearly is on the h-line $F F^{\perp}$, where $F^{\perp}$ is the foot of $F$ on the h-line $\ell$. So we can restrict without loss of generality the investigation of symmetric conical curves $\mathcal{C}_{F, \ell}^{\varepsilon}$ in $(\mathcal{D}, \delta)$ to those ones for which directrix $\ell$ is $\overline{\left(m,-\sqrt{1-m^{2}}\right)\left(m, \sqrt{1-m^{2}}\right)}$ for some $m \in(-1,1)$, the center is $O=(0,0)$, and the focus $F$ is $(f, 0)$, where $f \in(m, 1)$. Thus we can use the formulas given in the previous section.

As the conical curve is symmetric in the $x$-axis, and it is symmetric in point $O$, it is symmetric about the $y$-axis too, so, substituting $-p$ into $p$, equation (2.15) gives

$$
\left(\frac{\left(\sqrt{\left(p+\frac{1}{m}\right)^{2}+q^{2}\left(1-\frac{1}{m^{2}}\right)}+\left(1+\frac{1}{m} p\right)\right)^{2}}{\left(1-p^{2}-q^{2}\right)\left(\frac{1}{m^{2}}-1\right)}\right)^{\epsilon}=\frac{\left(f p+1+\sqrt{q^{2}\left(1-f^{2}\right)+(p+f)^{2}}\right)^{2}}{\left(1-f^{2}\right)\left(1-q^{2}-p^{2}\right)}
$$

Dividing (2.15) with this equation and taking the square root result in

$$
\left(\frac{\sqrt{\left(p-\frac{1}{m}\right)^{2}+q^{2}\left(1-\frac{1}{m^{2}}\right)}+\left(1-\frac{1}{m} p\right)}{\sqrt{\left(p+\frac{1}{m}\right)^{2}+q^{2}\left(1-\frac{1}{m^{2}}\right)}+\left(1+\frac{1}{m} p\right)}\right)^{\epsilon}=\frac{f p-1-\sqrt{q^{2}\left(1-f^{2}\right)+(p-f)^{2}}}{f p+1+\sqrt{q^{2}\left(1-f^{2}\right)+(p+f)^{2}}},
$$

If $q=0$, then $(2.15)$ gives

$$
\left(\frac{\left(\frac{1}{m}-1\right)(1+p)}{\left(\frac{1}{m}+1\right)(1-p)}\right)^{\epsilon}=\frac{(f p-1-|p-f|)^{2}}{\left(1-f^{2}\right)\left(1-p^{2}\right)}= \begin{cases}\frac{(1-f)(1+p)}{(1+f)(1-p)}, & \text { if } p>f \\ \frac{(1+f)(1-p)}{(1-f)(1+p)}, & \text { if } p<f\end{cases}
$$

After some rearrangement this becomes

$$
\frac{1 \pm f}{1 \mp f}\left(\frac{1-m}{1+m}\right)^{\epsilon}=\left(\frac{1+p}{1-p}\right)^{-\epsilon \pm 1}, \text { where } \pm 1=\frac{p-f}{|p-f|} .
$$


If $p$ is a solution of these equations, then the symmetry in $O$ implies, that $-p$ is also a solution of (2.18).

Suppose the two solutions $\pm p$ belong to the equation with the same sign of $\varepsilon$. If $\pm p$ are on the same side of $f$, then $p=0$, a contradiction follows. If $\pm p$ are on different sides of $f$, then

$$
\frac{1+f}{1-f}\left(\frac{1-m}{1+m}\right)^{\epsilon}=\left(\frac{1+p}{1-p}\right)^{-\epsilon+1}, \text { and } \frac{1-f}{1+f}\left(\frac{1-m}{1+m}\right)^{\epsilon}=\left(\frac{1-p}{1+p}\right)^{-\epsilon-1}=\left(\frac{1+p}{1-p}\right)^{\epsilon+1} .
$$

Division and multiplication of the first equation by the second one give

$$
\frac{1+f}{1-f}=\left(\frac{1-p}{1+p}\right)^{\epsilon} \text { and }\left(\frac{1-m}{1+m}\right)^{\epsilon}=\frac{1-p}{1+p}
$$

respectively. Substituting the second equation into the first one results in

$$
\frac{1+f}{1-f}=\left(\frac{1-m}{1+m}\right)^{\varepsilon^{2}}
$$

Note that the sign of $\varepsilon$ in (2.19) is irrelevant regarding the solutions. If $\varepsilon=1$, the second equation gives $f=-m$, hence $O$ is the midpoint of the segment of $F$ and its foot on $\ell$, so $p=0$, a contradiction.

Suppose the two solutions $\pm p$ belong to the equation with different signs of $\varepsilon$. If $\pm p$ are on the same side of $f$, then

$$
\frac{1 \pm f}{1 \mp f}\left(\frac{1-m}{1+m}\right)^{\varepsilon}=\left(\frac{1+p}{1-p}\right)^{-\varepsilon \pm 1}, \text { and } \frac{1 \pm f}{1 \mp f}\left(\frac{1-m}{1+m}\right)^{-\varepsilon}=\left(\frac{1-p}{1+p}\right)^{\varepsilon \pm 1}
$$

follow, where $\pm 1=\frac{p-f}{|p-f|}=\frac{-p-f}{|p+f|}$. Division and multiplication of the first equation by the second one give

$$
\left(\frac{1-m}{1+m}\right)^{ \pm \varepsilon}=\frac{1+p}{1-p}, \text { and } \frac{1 \pm f}{1 \mp f}=\left(\frac{1+p}{1-p}\right)^{\varepsilon}
$$

respectively. Rearranging the first equation, then substituting it into the second one results in

$$
\left(\frac{1 \mp m}{1 \pm m}\right)^{\varepsilon}=\frac{1+p}{1-p}, \text { and } \frac{1 \pm f}{1 \mp f}=\left(\frac{1 \mp m}{1 \pm m}\right)^{\varepsilon^{2}}
$$

respectively. If $\varepsilon=1$, the second equation gives $f=-m$, hence $O$ is the midpoint of the segment of $F$ and its foot on $\ell$, so $p=0$, a contradiction.

If $\pm p$ are on different sides of $f$, we may suppose that $p>f$, and so $-p<f$. Then

$$
\frac{1+f}{1-f}\left(\frac{1-m}{1+m}\right)^{\varepsilon}=\left(\frac{1+p}{1-p}\right)^{-\varepsilon+1}, \text { and } \frac{1-f}{1+f}\left(\frac{1-m}{1+m}\right)^{-\varepsilon}=\left(\frac{1-p}{1+p}\right)^{\varepsilon-1}
$$


follows, where $\frac{p-f}{|p-f|}=\frac{p+f}{|p+f|}$. Division and multiplication of the first equation by the second one give

$$
\frac{1+f}{1-f}\left(\frac{1-m}{1+m}\right)^{\varepsilon}=1, \quad \text { and } 1=\left(\frac{1+p}{1-p}\right)^{1-\varepsilon}
$$

respectively. This is obviously a contradiction.

Thus we have either $\varepsilon \in(0,1)$ or $\varepsilon \in(1, \infty)$, the elliptic or the hyperbolic case, respectively. Further, we have for the pair of points either (2.19) and (2.20), or (2.21) and (2.22), respectively. Moreover, $\pm p$ falls in different sides of $f$, and in the same side of $f$, respectively.

Theorem 2.2 ([12]). No conical curve of the hyperbolic plane can be symmetric.

Proof. Assume first the elliptic case, so that $\varepsilon \in(0,1)$.

Rearrangement of (2.17) gives

$$
\left(1+\frac{-\frac{2}{m} p}{\sqrt{\left(p+\frac{1}{m}\right)^{2}+q^{2}\left(1-\frac{1}{m^{2}}\right)}+\left(1+\frac{1}{m} p\right)}\right)^{\epsilon}=\frac{2 f p}{f p+1+\sqrt{q^{2}\left(1-f^{2}\right)+(p+f)^{2}}}-1,
$$

This is contradictory, because $p \rightarrow 0$ causes the left-hand side to tend to 1 , and the right-hand side to tend to -1 .

Assume now the hyperbolic case, so that $\varepsilon>1$.

Rearrangement of (2.17) gives for $p^{2}+q^{2} \rightarrow 1$ that

$$
\left(\frac{\left|1-\frac{1}{m} p\right|+\left(1-\frac{1}{m} p\right)}{\left|1+\frac{1}{m} p\right|+\left(1+\frac{1}{m} p\right)}\right)^{\epsilon}=\frac{f p-1-|f p-1|}{f p+1+|f p+1|}
$$

Since $|f p|<1$, the right-hand side vanishes, hence also the left-hand side vanishes, so $\frac{1}{m} p>1$. This is a contradiction because it can not be valid for both $p$ and $-p$.

The contradictions prove the statement.

\subsection{Quadratic conical curves on the sphere}

Let $\hat{O}$ be the polar of the great circle $\hat{\ell}$ on the $\mathcal{S}^{2}$. Let $\hat{F}$ be in the half sphere $\mathcal{S}_{\hat{O}}^{2}$ of $\hat{\ell}$ that contains $\hat{O}$. Let $\hat{P}$ be on the half circle $\mathcal{G}_{\hat{O}}^{2}$ of the great circle of $\hat{O}$ and $\hat{F}$ that is contained by $\mathcal{S}_{\hat{O}}^{2}$. Fix the coordinate system in the plane of $\mathcal{G}_{\hat{O}}^{2}$ such that $(0,0)$ is the center of $\mathcal{G}_{\hat{O}}^{2}, \hat{O}=(0,1), \hat{F}=(\cos \varphi, \sin \varphi)$ and $\hat{P}=(\cos \varpi, \sin \varpi)$ for some $\varphi \in(0, \pi / 2)$ 
and $\varpi \in(-\pi / 2, \pi / 2)$. Then $\hat{P} \in \hat{\mathcal{C}}_{\hat{\delta} ; \hat{F}, \hat{\ell}}^{\varepsilon}$ if and only if

$$
\varepsilon= \begin{cases}\frac{\varpi-\varphi}{\pi / 2-\varpi}, & \text { if } \varpi \in(\varphi, \pi / 2), \\ \frac{\varphi-\varpi}{\pi / 2-\varpi}, & \text { if } \varpi \in(0, \varphi), \\ \frac{\varphi-\varpi}{\pi / 2+\varpi}, & \text { if } \varpi \in(-\pi / 2,0] .\end{cases}
$$

If $\varpi \in(\varphi, \pi / 2)$, then $\frac{\varpi-\varphi}{\pi / 2-\varpi}=\frac{\pi / 2-\varphi}{\pi / 2-\varpi}-1$ is a strictly monotone increasing function of $\varpi$ that vanishes when $\varpi=\varphi$ and tends to infinity when $\varpi \rightarrow \pi / 2$.

So there is exactly one $\varpi \in(\varphi, \pi / 2)$ for which $\hat{P} \in \hat{\mathcal{C}}_{\hat{\delta} ; \hat{F}, \hat{\ell}}^{\varepsilon}$

If $\varpi \in(0, \varphi)$, then $\frac{\varphi-\varpi}{\pi / 2-\varpi}=1-\frac{\pi / 2-\varphi}{\pi / 2-\varpi}$ is a strictly monotone decreasing function of $\varpi$ that tends to $\frac{\varphi}{\pi / 2}$ when $\varpi \rightarrow 0$ and vanishes when $\varpi=\varphi$.

If $\varpi \in(-\pi / 2,0]$, then $\frac{\varphi-\varpi}{\pi / 2+\varpi}=\frac{\pi / 2+\varphi}{\pi / 2+\varpi}-1$ is a strictly monotone decreasing function of $\varpi$ that tends to infinity when $\varpi \rightarrow \pi / 2$ and is $\frac{\varphi}{\pi / 2}$ when $\varpi \rightarrow 0$.

Thus there is exactly one $\varpi \in(-\pi / 2, \varphi)$ for which $\hat{P} \in \hat{\mathcal{C}}_{\hat{\delta} ; \hat{F}, \hat{\ell}}^{\varepsilon}$.

Let $\mathcal{C}_{F, \ell}^{\varepsilon}:=\Gamma_{\hat{O}}\left(\hat{\mathcal{C}}_{\hat{\delta} ; \hat{F}, \hat{\ell}}^{\varepsilon}\right), O:=\Gamma_{\hat{O}}(\hat{O}), F:=\Gamma_{\hat{O}}(\hat{F})$, and $\ell:=\Gamma_{\hat{O}}(\hat{\ell})$. Choose the coordinate system so that $O=(0,0,1)$ and $F=(f, 0,1)$, where $f>0$. Figure 2.5 shows what we have on the plane $\mathcal{P}:=T_{\hat{O}} \mathcal{S}^{2}=\{(x, y, z): z=1\}$.

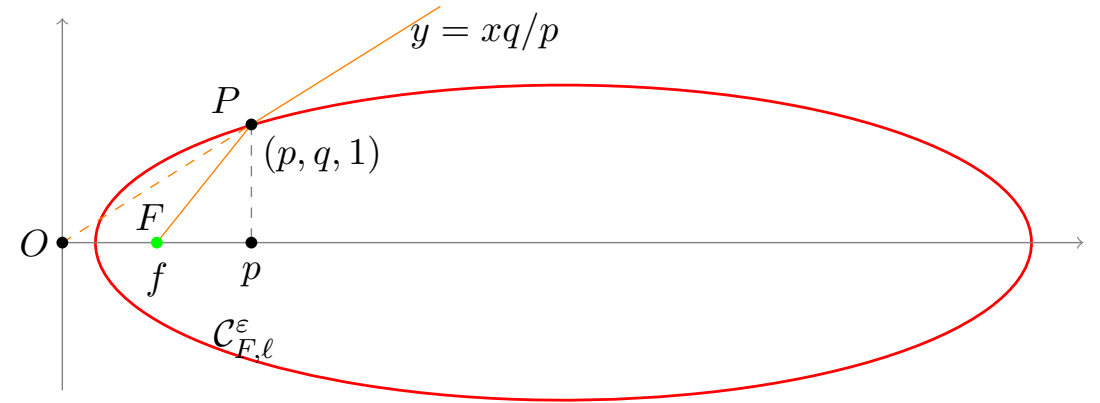

Figure 2.5: Projected conical curve $\mathcal{C}_{F, \ell}^{\varepsilon}$, if the directrix $\ell$ is in the infinity and the focus $F$ is at $(f, 0)$, where $f>0$.

To calculate the points $(p, q, 1)=P=\Gamma_{\hat{O}}(\hat{P})$ of $\mathcal{C}_{F, \ell}^{\varepsilon}$ we have to calculate $\delta(P, \ell)$ and $\delta(F, P)$, where $P \in \mathcal{C}_{F, \ell}^{\varepsilon}$. Observe that the line through $O$ and $P$ is the gnomonic image of the great circle that is perpendicular to $\hat{\ell}$ and going through $\Gamma_{\hat{O}}^{-1}(P)$. Thus, by (1.4), we have

$$
\delta(P, \ell)=\frac{\pi}{2}-\delta(P, O)=\frac{\pi}{2}-\arccos \frac{1}{\sqrt{p^{2}+q^{2}+1}} .
$$

For the distance of $P$ from the focus we obtain from (1.4) that

$$
\delta(P, F)=\delta(P,(f, 0,1))=\arccos \frac{p f+1}{\sqrt{f^{2}+1} \sqrt{p^{2}+q^{2}+1}} .
$$


According to $\left(D_{1}\right)$ equations (2.26) and (2.27) give that

$$
\varepsilon\left(\frac{\pi}{2}-\arccos \frac{1}{\sqrt{p^{2}+q^{2}+1}}\right)=\arccos \frac{p f+1}{\sqrt{f^{2}+1} \sqrt{p^{2}+q^{2}+1}}
$$

is the equation of $\mathcal{C}_{F, \ell}^{\varepsilon}$. Figure 2.6 shows how $\mathcal{C}_{F, \ell}^{\varepsilon}$ looks like for different values of $\varepsilon$.

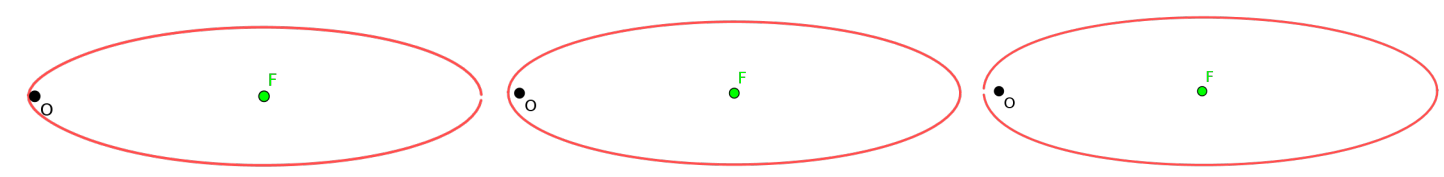

Figure 2.6: An elliptic $(\varepsilon=0.90)$, parabolic $(\varepsilon=1)$, and hyperbolic $(\varepsilon=1.1)$ conical curve in the projected model of the sphere.

The parabolic conical curves (i.e. $\varepsilon=1$ ) are quadratic because taking the cosine of (2.28) results in

$$
\sqrt{1-\frac{1}{p^{2}+q^{2}+1}}=\left|\frac{p f+1}{\sqrt{f^{2}+1} \sqrt{p^{2}+q^{2}+1}}\right|,
$$

the square of which is the clearly quadratic equation $\left(p^{2}+q^{2}\right)\left(f^{2}+1\right)=p f+1$.

To find all the quadratic conical curves,

$$
\text { from now on we assume that } \mathcal{C}_{F, \ell}^{\varepsilon} \text { is quadratic, }
$$

hence satisfies an equation of the form $\bar{a} x^{2}+\bar{b} x y+\bar{c} y^{2}+\bar{d} x+\bar{e} y+\bar{f}=0$, where the coefficients are real and $\bar{a} \geq 0$.

As every conical curve $\mathcal{C}_{F, \ell}^{\varepsilon}$ is symmetric in the $x$-axis, the quadratic equation should be invariant under changing $y$ to $-y$, so $\bar{b}=\bar{e}=0$ follows. Then the equation is of the form $\bar{a} x^{2}+\bar{c} y^{2}+\bar{d} x+\bar{g}=0$, hence $\bar{c} \neq 0$, because otherwise the curve will degenerate into straight lines. So the quadratic equation simplifies to

$$
a x^{2}+y^{2}+b x+c=0, \quad a \geq 0 .
$$

As this is an ellipse, because it is bounded and intersect line $O P$ in exactly two point, we deduce that

$$
a>0 \text { and } b^{2}>4 a c .
$$

Thus, for a point $P$ of $\mathcal{C}_{F, \ell}^{\varepsilon}$ we have $q^{2}=-a p^{2}-b p-c$. Putting this into (2.28) gives the identity

$$
\varepsilon\left(\frac{\pi}{2}-\arccos \frac{1}{\sqrt{(1-a) p^{2}-b p+1-c}}\right)=\arccos \frac{(p f+1) / \sqrt{f^{2}+1}}{\sqrt{(1-a) p^{2}-b p+1-c}} .
$$


Differentiating this with respect to $p$ gives

$$
\begin{aligned}
& \varepsilon \frac{-\frac{2(1-a) p-b}{2\left((1-a) p^{2}-b p+1-c\right)^{3 / 2}}}{\sqrt{1-\frac{1}{(1-a) p^{2}-b p+1-c}}} \\
& \quad=-\frac{-\frac{(2(1-a) p-b)(1+f p)}{2 \sqrt{1+f^{2}}\left((1-a) p^{2}-b p+1-c\right)^{3 / 2}}+\frac{f}{\sqrt{1+f^{2}} \sqrt{(1-a) p^{2}-b p+1-c}}}{\sqrt{1-\frac{(1+f p)^{2}}{\left(1+f^{2}\right)\left((1-a) p^{2}-b p+1-c\right)}}} .
\end{aligned}
$$

Simplifying the ratios and multiplying both sides by $2\left(1-c-b p+(1-a) p^{2}\right)$ give the equivalent form

$$
\begin{aligned}
& \varepsilon \frac{2(1-a) p-b}{\sqrt{(1-a) p^{2}-b p-c}} \\
& \quad=\frac{-(2(1-a) p-b)(1+f p)+2 f\left((1-a) p^{2}-b p+1-c\right)}{\sqrt{\left((1-a) p^{2}-b p+1-c\right)\left(1+f^{2}\right)-(1+f p)^{2}}} .
\end{aligned}
$$

After the additions and multiplications are completed this becomes

$$
\varepsilon \frac{2(1-a) p-b}{\sqrt{(1-a) p^{2}-b p-c}}=\frac{-(f b+2(1-a)) p+2 f(1-c)+b}{\sqrt{\left((1-a) p^{2}-b p+1-c\right)\left(1+f^{2}\right)-(1+f p)^{2}}} .
$$

Multiplying both sides of (2.34) by the product of the denominators and squaring gives

$$
\begin{gathered}
\varepsilon^{2}(2(1-a) p-b)^{2}\left(\left(1-a\left(1+f^{2}\right)\right) p^{2}-\left(2 f+b\left(1+f^{2}\right)\right) p+\left(f^{2}-c\left(1+f^{2}\right)\right)\right) \\
=((f b+2(1-a)) p-(b+2 f(1-c)))^{2}\left((1-a) p^{2}-b p-c\right) .
\end{gathered}
$$

This equation is valid on an interval of $p$, so the coefficients of the polynomials on the sides are equal, hence

$$
\begin{array}{cc}
\left(p^{4}\right) & 4 \varepsilon^{2}(1-a)^{2}\left(1-a\left(1+f^{2}\right)\right)=(1-a)(f b+2(1-a))^{2} \\
\left(p^{3}\right) & 4 \varepsilon^{2}\left((1-a)^{2}\left(2 f+b\left(1+f^{2}\right)\right)+b(1-a)\left(1-a\left(1+f^{2}\right)\right)\right) \\
= & b(f b+2(1-a))^{2}+2(1-a)(b+2 f(1-c))(f b+2(1-a)) \\
\left(p^{2}\right) & \left.+4(1-a)^{2}\left(f^{2}-c\left(1+f^{2}\right)\right)\right) \\
& \varepsilon^{2}\left(b^{2}\left(1-a\left(1+f^{2}\right)\right)+4 b(1-a)\left(2 f+b\left(1+f^{2}\right)\right)+\right. \\
& =-c(f b+2(1-a))^{2}+2 b(b+2 f(1-c))(f b+2(1-a))+ \\
\left(p^{1}\right) & +(1-a)(b+2 f(1-c))^{2} \\
& 4 \varepsilon^{2}\left(b(1-a)\left(f^{2}-c\left(1+f^{2}\right)\right)+b^{2}\left(2 f+b\left(1+f^{2}\right)\right)\right) \\
\left(p^{0}\right) & b(b+2 f(1-c))^{2}-2 c(b+2 f(1-c))(f b+2(1-a)) \\
\varepsilon^{2} b^{2}\left(f^{2}-c\left(1+f^{2}\right)\right)=-c(b+2 f(1-c))^{2},
\end{array}
$$

where $\varepsilon, f>0$ are fixed, and $a>0, b^{2}>4 a c$ by $(2.30)$. 
If $b=0$, then $\left(p^{4}\right)$ implies $a=1$, and $\left(p^{0}\right)$ implies $c=0$ or $c=1$. In both cases $\mathcal{C}_{F, \ell}^{\varepsilon}$ is empty by (2.29), and this contradiction proves $b \neq 0$.

If $c=0$, then $\left(p^{0}\right)$ implies $b=0$, a contradiction, so $c \neq 0$.

If $a=1$, then $\left(p^{3}\right)$ gives $b=0$, a contradiction, so $a \neq 1$.

Dividing $\left(p^{4}\right)$ with $1-a$ gives

$$
4 \varepsilon^{2}(1-a)\left(1-a\left(1+f^{2}\right)\right)=(f b+2(1-a))^{2},
$$

Multiplying the sides of (2.36) with the opposite sides of $\left(p^{0}\right)$, respectively, we obtain

$$
\begin{aligned}
-4 c(1-a)(b+2 f(1-c))^{2} & \left(1-a\left(1+f^{2}\right)\right) \\
= & b^{2}\left(f^{2}-c\left(1+f^{2}\right)\right)(f b+2(1-a))^{2} .
\end{aligned}
$$

Multiplying (2.36) with $b$ and subtracting the result from $\left(p^{3}\right)$ give, after a light simplification, that

$$
2 \varepsilon^{2}(1-a)\left(2 f+b\left(1+f^{2}\right)\right)=(b+2 f(1-c))(f b+2(1-a)) .
$$

The right-hand side of the square of (2.38) multiplied by $-c$ is the product of the righthand sides of $\left(p^{0}\right)$ and $(2.36)$, so we get

$$
-4 c(1-a)\left(2 f+b\left(1+f^{2}\right)\right)^{2}=b^{2}\left(f^{2}-c\left(1+f^{2}\right)\right)\left(1-a\left(1+f^{2}\right)\right) .
$$

Multiplying (2.38) by $2 b$ and subtracting the product from $\left(p^{2}\right)$ give

$$
\begin{aligned}
\varepsilon^{2}\left(b^{2}\left(1-a\left(1+f^{2}\right)\right)\right. & \left.+4(1-a)^{2}\left(f^{2}-c\left(1+f^{2}\right)\right)\right) \\
& =(1-a)(b+2 f(1-c))^{2}-c(f b+2(1-a))^{2} .
\end{aligned}
$$

Multiplying (2.36) by $c$ and adding to this give

$$
\begin{aligned}
\varepsilon^{2}\left(\left(b^{2}+4 c(1-a)\right)\left(1-a\left(1+f^{2}\right)\right)+4(1-a)^{2}\right. & \left.\left(f^{2}-c\left(1+f^{2}\right)\right)\right) \\
& =(1-a)(b+2 f(1-c))^{2} .
\end{aligned}
$$

Multiplying this with $c$ and adding to the product of $\left(p^{0}\right)$ and $(1-a)$ result in

$$
\left.c\left(b^{2}+4 c(1-a)\right)\left(1-a\left(1+f^{2}\right)\right)+(1-a)\left(b^{2}+4 c(1-a)\right)\left(f^{2}-c\left(1+f^{2}\right)\right)\right)=0,
$$

hence

$$
b^{2}+4 c(1-a)=0 \text { or } 1=a+c .
$$


Add $\left(p^{1}\right)$ times $1-a,(2.41)$ times $-b$ and (2.38) times $2 c(1-a)$. The result is

$$
4\left(b^{2}+c(1-a)\right)(1-a)\left(2 f+b\left(1+f^{2}\right)\right)=b\left(b^{2}+4 c(1-a)\right)\left(1-a\left(1+f^{2}\right)\right) .
$$

- Assume that $1=a+c$ fulfills in (2.42).

Then $b^{2}+4 a(1-c)=b^{2}+4 a^{2}>0$, and it is also easy to show that $f^{2}-c\left(1+f^{2}\right)=$ $-\left(1-a\left(1+f^{2}\right)\right)$. Further, $(2.37)$ gives $4 c^{2}(b+2 f(1-c))^{2}=b^{2}(f b+2 c)^{2}$, hence

$$
\begin{aligned}
0 & =b^{2}(f b+2 c)^{2}-4 c^{2}(b+2 f(1-c))^{2} \\
& =(b(f b+2 c)-2 c(b+2 f(1-c)))(b(f b+2 c)+2 c(b+2 f(1-c))) \\
& =f\left(b^{2}-4 c(1-c)\right)(b(f b+2 c)+2 c(b+2 f(1-c))) .
\end{aligned}
$$

Since $b^{2}>4 c(1-c)$ by $(2.30)$, we obtain

$$
-b(f b+2 c)=2 c(b+2 f(1-c)) .
$$

From $\left(p^{3}\right)$ we obtain

$$
\begin{aligned}
4 \varepsilon^{2} c\left(c\left(2 f+b\left(1+f^{2}\right)\right)\right. & \left.-b\left(f^{2}-c\left(1+f^{2}\right)\right)\right) \\
& \left.=b(f b+2 c)^{2}+2 c(f b+2 c)(b+2 f(1-c))\right) .
\end{aligned}
$$

The right-hand side of this equation vanishes by (2.44), so we arrive at

$$
c\left(2 f+b\left(1+f^{2}\right)\right)=b\left(f^{2}-c\left(1+f^{2}\right)\right) .
$$

Since $1-a=c,(2.38)$ reads

$$
2 \varepsilon^{2} c\left(2 f+b\left(1+f^{2}\right)\right)=(b+2 f(1-c))(f b+2 c) .
$$

Multiplying this with $2 c$ and using (2.44) results in

$$
4 \varepsilon^{2} c^{2}\left(2 f+b\left(1+f^{2}\right)\right)=2 c(b+2 f(1-c))(f b+2 c)=-b(f b+2 c)^{2} .
$$

Using (2.46) and then (2.36) this gives

$$
4 \varepsilon^{2} c b\left(f^{2}-c\left(1+f^{2}\right)\right)=-(f b+2 c)^{2} b=4 \varepsilon^{2} c\left(1-(1-c)\left(1+f^{2}\right)\right) b .
$$

Thus $f^{2}-c\left(1+f^{2}\right)=1-(1-c)\left(1+f^{2}\right)$, so, by (2.42) and (2.46), we have

$$
c=\frac{f^{2}}{1+f^{2}}, \quad a=\frac{1}{1+f^{2}}, \quad \text { and } \quad b=\frac{-2 f}{1+f^{2}} .
$$

This, however gives $b^{2}=4 a c$ that contradicts (2.30). 
- Assume that $1 \neq a+c$ and $b^{2}+4 c(1-a)=0$ fulfills in $(2.42)$.

As a first consequence, we get from (2.43) that

$$
b^{2}+c(1-a)=0 \text { or } 2 f+b\left(1+f^{2}\right)=0 .
$$

In the former case the assumption implies $c(1-a)=0$, so either $c=0$ or $a=1$, which was already closed out, so we deduce $b=\frac{-2 f}{1+f^{2}}$. From this (2.39) implies immediately that $0=\left(f^{2}-c\left(1+f^{2}\right)\right)\left(1-a\left(1+f^{2}\right)\right)$, so

$$
c=\frac{f^{2}}{1+f^{2}} \text { or } a=\frac{1}{1+f^{2}} \text {. }
$$

Then, by the assumption we respectively obtain that

$$
a=\frac{4 c+b^{2}}{4 c}=\frac{2+f^{2}}{1+f^{2}} \text { and } c=\frac{-b^{2}}{4(1-a)}=\frac{-1}{1+f^{2}} .
$$

In the first case we get

$$
b^{2}-4 a c=\frac{4 f^{2}}{\left(1+f^{2}\right)^{2}}-4 \frac{2+f^{2}}{1+f^{2}} \frac{f^{2}}{1+f^{2}}=\frac{4 f^{2}}{\left(1+f^{2}\right)^{2}}\left(1-\left(2+f^{2}\right)\right)=\frac{-4 f^{2}}{1+f^{2}}<0
$$

that contradicts (2.30), so we deduce

$$
c=\frac{-1}{1+f^{2}}, \quad a=\frac{1}{1+f^{2}}, \quad \text { and } \quad b=\frac{-2 f}{1+f^{2}} .
$$

With these values $\left(p^{0}\right)$ gives $\varepsilon=1$. $\left(p^{1}\right)$ gives also $\varepsilon=1$.

Thus the second case in (2.42) implies a contradiction, while it follows from the first case of (2.42) that the conical curve is parabolic.

The contradiction means that the system of equations $\left(p^{0}\right)-\left(p^{4}\right)$ does not have a solution, so the polynomials of the sides in (2.35) are different, hence the conical curves in this case are not quadratic.

Theorem 2.3 ([13]). A conical curve on the sphere is quadratic if and only if either the focus is the pole of the directrix, or the focus is not the pole of the directrix, but the conical curve is parabolic, i.e. $\varepsilon=1$.

\subsection{Symmetric conical curves on the sphere}

Firstly we notice that the conical curve on the sphere is a hypersphere, hence symmetric if the focus is the pole of the directrix, so we assume for the sake of a later contradiction that

$\hat{F}$ is not the pole of $\hat{\ell}$, and $\hat{\mathcal{C}}_{\hat{\delta} ; \hat{F}, \hat{\ell}}^{\varepsilon}$ is symmetric in a point $\hat{C}$. 
Such a point of symmetry $\hat{C}$ clearly is on the great circle of $\hat{F} \hat{F}^{\perp}$, where $\hat{F}^{\perp}$ is the unique foot of $\hat{F}$ on the great circle $\hat{\ell}$.

Take the gnomonic projection $\Gamma_{\hat{C}}$. Let $\mathcal{C}_{F, \ell}^{\varepsilon}:=\Gamma_{\hat{C}}\left(\hat{\mathcal{C}}_{\hat{\delta} ; \hat{F}, \hat{\ell}}^{\varepsilon}\right), P:=\Gamma_{\hat{C}}(\hat{P})$ and $P^{\perp}:=$ $\Gamma_{\hat{C}}\left(\hat{P}^{\perp}\right)$ for any point $P$, and $\ell:=\Gamma_{\hat{C}}(\hat{\ell})$. Choose the coordinate system so that $C=$ $(0,0,1), F=(f, 0,1)$, and $\ell=\{(x, y, z): x=m \wedge z=1\}$. Figure 2.7 shows what we have on the plane $\mathcal{P}:=T_{\hat{C}} \mathcal{S}^{2}=\{(x, y, z): z=1\}$.

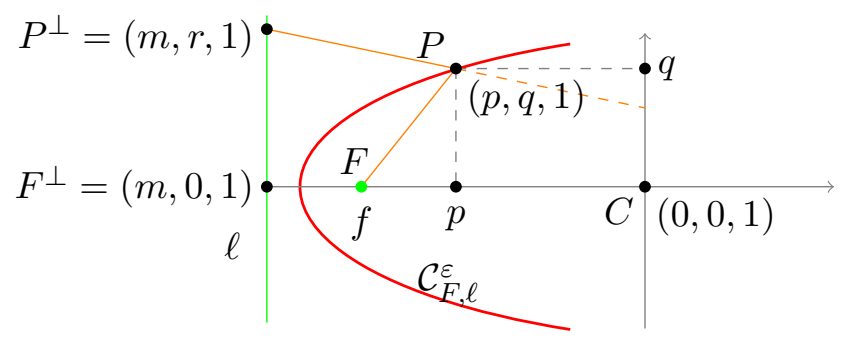

Figure 2.7: Projected conical curve $\mathcal{C}_{F, \ell}^{\varepsilon}$, if the directrix $\ell$ is parallel to the $y$-axis and the focus $F$ is at $(f, 0)$, where $f<0$.

The advantage of taking the gnomonic projection $\Gamma_{\hat{C}}$ is that $\hat{\mathcal{C}}_{\hat{\delta} ; \hat{F}, \hat{\ell}}^{\hat{\varepsilon}}$ is symmetric about $\hat{C}$ in the spherical meaning if and only if $\mathcal{C}_{F, \ell}^{\varepsilon}$ is symmetric about $C$ in the Euclidean meaning.

Since $\hat{F}^{\perp} \hat{P}^{\perp} \hat{P}$ is a right triangle on the sphere, the cosine rule for the spherical triangle [21] gives $\cos \hat{\delta}\left(\hat{F}^{\perp}, \hat{P}\right)=\cos \hat{\delta}\left(\hat{F}^{\perp}, \hat{P}^{\perp}\right) \cos \hat{\delta}\left(\hat{P}^{\perp}, \hat{P}\right)$. Then (1.4) gives

$$
\cos \left(\hat{\delta}\left(\hat{F}^{\perp}, \hat{P}\right)\right)=\frac{\left\langle\hat{F}^{\perp}, \hat{P}\right\rangle}{\left|\hat{F}^{\perp}\right||\hat{P}|}, \cos \left(\hat{\delta}\left(\hat{F}^{\perp}, \hat{P}^{\perp}\right)\right)=\frac{\left\langle\hat{F}^{\perp}, \hat{P}^{\perp}\right\rangle}{\left|\hat{F}^{\perp}\right|\left|\hat{P}^{\perp}\right|}, \cos \left(\hat{\delta}\left(\hat{P}^{\perp}, \hat{P}\right)\right)=\frac{\left\langle\hat{P}^{\perp}, \hat{P}\right\rangle}{\left|\hat{P}^{\perp}\right||\hat{P}|},
$$

so we obtain $\left\langle\hat{F}^{\perp}, \hat{P}\right\rangle\left|\hat{P}^{\perp}\right|^{2}=\left\langle\hat{F}^{\perp}, \hat{P}^{\perp}\right\rangle\left\langle\hat{P}^{\perp}, \hat{P}\right\rangle$, i.e.

$$
(m p+1)\left(m^{2}+r^{2}+1\right)=\left(m^{2}+1\right)(m p+r q+1) .
$$

This equation is equivalent to equation $r\left(r(m p+1)-q\left(m^{2}+1\right)\right)=0$ that gives

$$
r=\frac{q\left(m^{2}+1\right)}{m p+1}
$$

Thus, by (1.4), we have

$$
\begin{aligned}
\delta(P, \ell) & =\delta(P,(m, r, 1)) \\
& =\arccos \frac{m p+r q+1}{\sqrt{m^{2}+r^{2}+1} \sqrt{p^{2}+q^{2}+1}}=\arccos \frac{(m p+1) \sqrt{m^{2}+r^{2}+1}}{\left(m^{2}+1\right) \sqrt{p^{2}+q^{2}+1}} \\
& =\arccos \frac{\sqrt{(m p+1)^{2}+q^{2}\left(m^{2}+1\right)}}{\sqrt{m^{2}+1} \sqrt{p^{2}+q^{2}+1}},
\end{aligned}
$$


where we used (2.55) and its predecessor. For the distance of $P$ from the focus we have (2.27).

According to $\left(D_{1}\right)$ equations $(2.56)$ and $(2.27)$ give

$$
\varepsilon \arccos \frac{\sqrt{(m p+1)^{2}+q^{2}\left(m^{2}+1\right)}}{\sqrt{m^{2}+1} \sqrt{p^{2}+q^{2}+1}}=\arccos \frac{p f+1}{\sqrt{f^{2}+1} \sqrt{p^{2}+q^{2}+1}} .
$$

Figure 2.8 shows how these conical curves look like by (2.28).

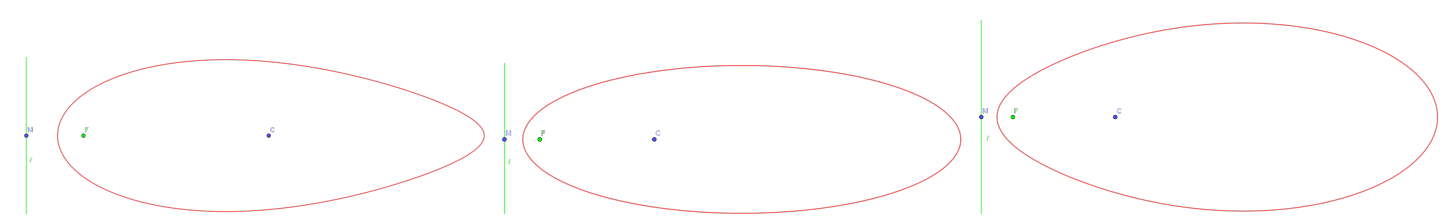

Figure 2.8: An elliptic $(\varepsilon=0.90)$, parabolic $(\varepsilon=1)$, and hyperbolic $(\varepsilon=1.1)$ conical curve in projected model of the sphere.

We now that there exist exactly two solutions of (2.57) for $q=0$, and by the symmetry these are $\pm p_{0}$. Thus $\pm p_{0}$ satisfies

$$
\varepsilon \arccos \frac{|m p+1|}{\sqrt{m^{2}+1} \sqrt{p^{2}+1}}=\arccos \frac{p f+1}{\sqrt{f^{2}+1} \sqrt{p^{2}+1}} .
$$

Let $m=\tan \mu, f=\tan \varphi$, and $p_{0}=\tan \varpi$. Substituting these values into (2.58) results in

$$
\varepsilon \arccos \frac{|1 \pm \tan \mu \tan \varpi|}{\sqrt{1+\tan ^{2} \mu} \sqrt{1+\tan ^{2} \varpi}}=\arccos \frac{1 \pm \tan \varphi \tan \varpi}{\sqrt{1+\tan ^{2} \varphi} \sqrt{1+\tan ^{2} \varpi}}
$$

i.e.

$$
\varepsilon \arccos |\cos \mu \cos \varpi \pm \sin \mu \sin \varpi|=\arccos (\cos \varphi \cos \varpi \pm \sin \varphi \sin \varpi),
$$

hence by the angle sum and difference identities [20] we get

$$
\varepsilon \arccos |\cos (\mu \mp \varpi)|=\arccos (\cos (\varphi \mp \varpi)),
$$

Thus, $\varepsilon \mu-\varphi= \pm \varpi(1-\varepsilon)$, hence $\varpi(1-\varepsilon)=0$. Since $\varpi \neq 0$, we get $\varepsilon=1$, so $\mu=\varphi$ that is a contradiction.

In sum, we have proved the following theorem.

Theorem 2.4 ([13]). A conical curve on the sphere is symmetric if and only if the focus is the pole of the directrix. 


\subsection{Conical ellipses and conical hyperbolas}

As every ellipse and every hyperbola in the hyperbolic plane is symmetric, every conical ellipse and every conical hyperbola is a symmetric conical curve, hence Theorem 2.2 implies the following.

Theorem 2.5. There is no conical ellipse or conical hyperbola in the hyperbolic plane.

As every ellipse and every hyperbola on the sphere is symmetric, every conical ellipse and every conical hyperbola is a symmetric conical curve, hence Theorem 2.4 implies the following.

Theorem 2.6. Every conical ellipse and every conical hyperbola on the sphere is a circle. 


\section{Bibliography}

[1] V. I. ARnold, Real algebraic geometry, Unitext, vol. 66, Springer, Heidelberg, 2013. Translated from the 2009 Russian original by Gerald G. Gould and David Kramer, Edited and with a foreword by Ilia Itenberg, Viatcheslav Kharlamov and Eugenii I. Shustin, La Matematica per il $3+2$.

[2] F. JR. Ayres, Projective geometry, Schaum's outline series, Schaum Pub. Co., 1967.

[3] H. Busemann, The geometry of geodesics, Academic Press Inc., New York, N. Y., 1955.

[4] H. Busemann, and P. J. Kelly, Projective geometry and projective metrics, Academic Press Inc., New York, N. Y., 1953.

[5] J. W. Cannon, W. J. Floyd, R. Kenyon, and W. R. Parry, Hyperbolic geometry, Flavors of geometry, Math. Sci. Res. Inst. Publ., vol. 31, Cambridge Univ. Press, Cambridge, 1997, pp. 59-115.

[6] M. P. Do Carmo, Differential geometry of curves 83 surfaces, Dover Publications, Inc., Mineola, NY, 2016.

[7] R. CAsse, Projective geometry: an introduction, Oxford University Press, Oxford, 2006.

[8] P. J. Kelly and L. J. Paige, Symmetric perpendicularity in Hilbert geometries, Pacific J. Math. 2 (1952), 319-322, available at https://projecteuclid. org/euclid.pjm/1103051777.

[9] Á. Kurusa, Support theorems for totally geodesic Radon transforms on constant curvature spaces, Proc. Amer. Math. Soc. 122 (1994), no. 2, 429-435, doi: 10.2307/ 2161033.

[10] Á. Kurusa, Conics in Minkowski geometries, Aequationes Math. 92 (2018), no. 5, 949-961, doi: 10.1007/s00010-018-0592-1.

[11] A. M. MAhDi, Quadratic conics in hyperbolic geometry, Int. J. Geom. 8 (2019), no. 2, 60-69, available at https://ijgeometry.com/wp-content/uploads/2019/ 09/60-69.pdf.

[12] A. M. MAhdi, Symmetric conics in hyperbolic geometry, Glob. J. Adv. Res. Class. Mod. Geom. 8 (2019), no. 2, 49-56, available at http://geometry-math-journal. ro/pdf/Volume8-Issue2/1.pdf. 
[13] A. M. Mahdi, Conics on the sphere, Int. J. Geom. 9 (2020), no. 2, 5-14, available at https://ijgeometry.com/wp-content/uploads/2020/.

[14] J. Radon, Über eine besondere Art ebener konvexer Kurven, Ber. Verh. Sächs. Ges. Wiss. Leipzig. Math.-Phys. Kl. 68 (1916), 123-128 (German).

[15] L. TAmÁssy, and K. BÉLteky, On the coincidence of two kinds of ellipses in Minkowskian spaces and in Finsler planes, Publ. Math. Debrecen 31 (1984), no. 3-4, $157-161$.

[16] L. TAmássy, and K. BÉlteky, On the coincidence of two kinds of ellipses in Riemannian and in Finsler spaces, Topics in differential geometry, Vol. I, II (Debrecen, 1984), Colloq. Math. Soc. János Bolyai, vol. 46, North-Holland, Amsterdam, 1988, pp. $1193-1200$.

[17] WikipediA, Dandelin spheres, available at https://en.wikipedia.org/wiki/ Dandelin_spheres.

[18] Wikipedia, Gnomonic projection, available at https://en.wikipedia.org/wiki/ Gnomonic_projection.

[19] Wikipedia, Hilbert's theorem (differential geometry), available at https://en. wikipedia.org/wiki/Hilbert's_theorem_(differential_geometry).

[20] Wikipedia, List of trigonometric identities, available at https://en.wikipedia. org/wiki/List_of_trigonometric_identities.

[21] Wikipedia, Spherical trigonometry: Cosine rules and sine rules, available at https://en.wikipedia.org/wiki/Spherical_trigonometry\#Cosine_rules_ and_sine_rules.

[22] J. A. Wolf, Spaces of constant curvature, Sixth, AMS Chelsea Publishing, Providence, RI, 2011.

[23] Wolframalpha, Solving equation:, available at https://www.wolframalpha.

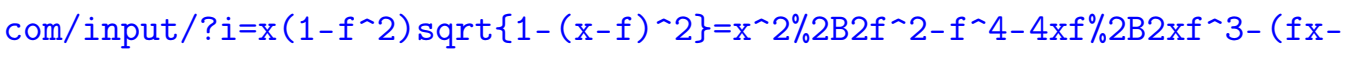
1) $|x-f| \operatorname{sqrt}\left\{2-f^{\wedge} 2\right\}$.

[24] Wolframalpha, Solving equation:, available at https://www.wolframalpha. com/input $/ ? i=\left(1-f^{\wedge} 2\right)(\operatorname{sqrt}\{1-(x-f) \sim 2\} \% 2 B x) \sim 2=\left(f x-1-(f-x) \operatorname{sqrt}\left\{2-f^{\wedge} 2\right\}\right)$ -2 .

[25] Wolframalpha, Solving equation:, available at https://www.wolframalpha. com/input/? $i=\left(1-f^{\wedge} 2\right)(\operatorname{sqrt}\{1-3(x-f) \sim 2\} \% 2 B x) \sim 2=(f x-1-(f-x) \operatorname{sqrt}\{4-3 f \wedge 2\})$ -2 . 


\title{
Notations
}

\author{
$\mathbb{R}$ the set of real numbers \\ $\mathbb{R}^{n}$ the $n$-dimensional real space \\ $\mathbb{P}^{n}$ the $n$-dimensional projective space \\ points $A, B, \ldots$ or a if the origin is fixed, \\ vectors $\overrightarrow{A B}$ or $\mathbf{a}$, \\ $\overline{A B}$ open segment with endpoints $A$ and $B$ \\ $\bar{A} B$ open ray starting from $A$ passing through $B$ \\ $A B$ the line through points $A$ and $B$; \\ $(A, B)$ open segment with endpoints $A$ and $B$ \\ $(A, B ; C)$ the affine ratio of the collinear points $A, B$ and $C$ \\ $(A, B ; C, D)$ the cross ratio of the collinear points $A, B$ and $C, D$ \\ $\mathcal{S}^{n-1}$ the sphere in the $n$-dimensional Euclidean space
}




\section{Summary}

According to [15], A. Moór raised the request for determining those Finsler manifolds in which the class of elliptic conical curves coincides with the class of ellipses, or the class of hyperbolic conical curves coincides with the class of hyperbolas. Tamássy and Bélteky found in [16, Theorem 2], that the only Finsler space where the class of elliptic conical curves coincides with the class of ellipses is the Euclidean space.

A similar problem was solved by Kurusa in [10, Theorem 6.1], where he proved that the only Minkowski geometry in which either a conical ellipsoid or a conical hyperboloid exists is the Euclidean one. At the end of his paper [10] Kurusa formulated the problem of determining projective-metric spaces in which

(a) some or all ellipses are conical, or

(b) some or all hyperbolas are conical.

Kurusa's main result [10, Theorem 6.1] was based on that, by [10, Theorem 4.2 and 4.3], the only Minkowski geometry in which a symmetric conical curve exists is the Euclidean one. Additionally, it is also proved in [10, Theorem 5.1] that the only Minkowski plane in which a quadratic conical curve exists is the Euclidean one. So Kurusa also raised the request to determine the projective-metric spaces in which

(c) some or all elliptic conical curves are symmetric, or

(d) some or all hyperbolic conical curves are symmetric, or

(e) some or all elliptic conical curves are quadratic, or

(f) some or all hyperbolic conical curves are quadratic.

All the requests remained unanswered for curved projective-metric spaces.

The purpose of my research was to answer Kurusa's requests for the curved constant curvature spaces. In the hyperbolic case there was no surprise, but it turned out in the spherical case that there are some very special conical curves.

The results in this dissertation are the fruit of my research. They were published in my papers [11], [12], and [13]. 
In a projective-metric space $(\mathcal{M}, d)$ we define

$\left(D_{1}\right)$ a conical curve as the set

$$
\mathcal{C}_{F, \mathcal{H}}^{\varepsilon}:=\left\{X \in \mathbb{R}^{n}: \varepsilon d(X, \mathcal{H})=d(F, X)\right\},
$$

where $\mathcal{H}$ is a hyperplane, the leading hyperplane or directrix, $F \notin \mathcal{H}$ is a point, the focus, and $\varepsilon>0$ is a number, the numeric eccentricity. A conical curve is said to be elliptic, parabolic and hyperbolic, if $\varepsilon<1, \varepsilon=1$ and $\varepsilon>1$, respectively.

For given fixed points $F_{1}, F_{2}$, the focuses, and number $a \neq d\left(F_{1}, F_{2}\right) / 2$, the radius, we define

$\left(D_{2}\right)$ the ellipsoid (ellipse in dimension 2) as the set

$$
\mathcal{E}_{d ; F_{1}, F_{2}}^{a}:=\left\{E: 2 a=d\left(F_{1}, E\right)+d\left(E, F_{2}\right)\right\}, \text { and }
$$

$\left(D_{3}\right)$ the hyperboloid (hyperbola in dimension 2) as the set

$$
\mathcal{H}_{d ; F_{1}, F_{2}}^{a}:=\left\{X: 2 a=\left|d\left(F_{1}, X\right)-d\left(X, F_{2}\right)\right|\right\} .
$$

By the triangle inequality, $a>d\left(F_{1}, F_{2}\right) / 2$ for the ellipsoid, and $a<d\left(F_{1}, F_{2}\right) / 2$ for the hyperboloid. Value $2 f:=d\left(F_{1}, F_{2}\right)$ is the eccentricity, and if the eccentricity vanishes, then the ellipsoid (ellipse) is called sphere (circle). Further, an ellipsoid (ellipse) or hyperboloid (hyperbola) is called conical if it is a conical curve.

Unlike the above definitions quadraticity is defined with no reference for the metric. We define

$\left(D_{4}\right)$ a quadratical curve as the set of points satisfying the equation of the form

$$
\mathcal{Q}_{\mathfrak{s}}^{\sigma}:=\left\{(x, y):\left\{\begin{array}{ll}
1=x^{2}+\sigma y^{2}, & \text { if } \sigma \in\{-1,1\}, \\
x=y^{2}, & \text { if } \sigma=0,
\end{array}\right\},\right.
$$

for some affine coordinate system $\mathfrak{s}$.

Quadratical curves are also called quadric, and a quadric is called elliptic, parabolic, and hyperbola, if $\sigma=1, \sigma=0$ and $\sigma=-1$, respectively.

A set $\mathcal{S} \subset \mathcal{M}$ in a projective-metric space $(\mathcal{M}, d)$ is called symmetric about a point $C \in \mathcal{M}$, if $X \in \mathcal{S}$ if and only if $Y \in \mathcal{S}$, where $C$ is in the metric midpoint of the segment $\overline{X Y}$, i.e. $2 d(X, C)=2 d(C, Y)=d(X, Y)$.

Section 2.1, "Quadratic conical curves in the hyperbolic plane", is based on my paper [11].

We say that a conical curve is quadratic if it fits on a quadric $\left(D_{q}\right)$, i.e. satisfies an equation of the form $\bar{a} x^{2}+\bar{b} x y+\bar{c} y^{2}+\bar{d} x+\bar{e} y+\bar{f}=0$, where the coefficients are real and $\bar{a} \geq 0$.

Theorem S.1 ([11]). No conical curve of the hyperbolic plane can be quadratic. 
The proof is a long and tricky calculation that determines the coefficients of the quadratic equation and leads to contradiction.

Section 2.2, "Symmetric conical curves in the hyperbolic plane", is based on my paper [12].

We say that a conical curve is symmetric if it is symmetric in a point.

Theorem S.2 ([12]). No conical curve of the hyperbolic plane can be symmetric.

For the proof we first determine with some tiring calculations the exponential equation of a conical curve in the Cayley-Klein model and then investigate the tangents of such curve if the conical curve is symmetric in the center of the model. Then properly chosen points on the conical curve show that the symmetry causes contradictions, hence proving the theorem.

Section 2.3, "Quadratic conical curves on the sphere", and Section 2.4, "Symmetric conical curves on the sphere", are based on the paper [13].

Theorem S.3 ([13]). A conical curve on the sphere is quadratic if and only if either the focus is the pole of the directrix, or the focus is not the pole of the directrix, but the conical curve is parabolic, i.e. $\varepsilon=1$.

The proof is a long and tricky calculation that determines the coefficients of the quadratic equation and leads to contradiction.

Theorem S.4 ([13]). A conical curve on the sphere is symmetric if and only if the focus is the pole of the directrix.

Section 2.5, "Conical ellipses and conical hyperbolas", contains some direct consequences of the above results.

As every ellipse and every hyperbola in the hyperbolic plane is symmetric, every conical ellipse and every conical hyperbola is a symmetric conical curve, hence Theorem S.2 implies the following.

Theorem S.5. There is no conical ellipse or conical hyperbola in the hyperbolic plane.

As every ellipse and every hyperbola on the sphere is symmetric, every conical ellipse and every conical hyperbola is a symmetric conical curve, hence Theorem S.4 implies the following.

Theorem S.6. Every conical ellipse and every conical hyperbola on the sphere is a circle. 


\section{Magyar nyelvü összefoglaló (Summary in Hungarian)}

Tamássy Lajos [15] cikke szerint Moór Artúr vetette fel azon Finsler sokaságok meghatározásának problémáját, amelyekben az elliptikus kúpszeletek osztálya megegyezik az ellipszisek osztályával, vagy a hiperbolikus kúpszeletek osztálya megegyezik a hiperbolák osztályával. Az elsố esetet Tamássy és Bélteky tisztázta [16, Theorem 2]: az egyetlen Finsler tér, amelyben az elliptikus kúpszeletek osztálya megegyezik az ellipszisek osztályával az euklideszi tér.

Hasonló probléma megoldását adta Kurusa Árpád is, amikor igazolta [10, Theorem 6.1], hogy az Euklidészi az egyetlen olyan Minkowski sík, amelyben egy kúpmetszet-görbe ellipszis vagy egy kúpmetszet-görbe hyperbola. A [10] cikke végén Kurusa felvetette azon projektív-metrikus terek meghatározásának problémáját, melyekben

(a) néhány vagy minden ellipszis kúpmetszet-görbe, vagy

(b) néhány vagy minden hyperbolas kúpmetszet-görbe.

Kurusa [10, Theorem 6.1] eredményének bizonyítása azon alapult, hogy a [10, Theorem 4.2 and 4.3] tételek szerint az Euklidészi az egyetlen olyan Minkowski sík, amelyben van szimmetrikus kúpmetszet-görbe. Továbbá a [10, Theorem 5.1] eredményben Kurusa azt is igazolta, hogy az Euklidészi az egyetlen olyan Minkowski sík, amelyben van kvadratikus kúpmetszet-görbe. Ezekből kiindulva Kurusa felvetette azon projektív-metrikus terek meghatározásának problémáját, melyekben

(c) néhány vagy minden elliptikus kúpmetszet-görbe szimmetrikus, vagy

(d) néhány vagy minden hiperbolikus kúpmetszet-görbe szimmetrikus, vagy

(e) néhány vagy minden elliptikus kúpmetszet-görbe kvadratikus, vagy

(f) néhány vagy minden hiperbolikus kúpmetszet-görbe kvadratikus.

Minden Kurusa által felvetett kérdés megválaszolatlanul maradt a görbült projektívmetrikus terekre.

Kutatásaim célja az volt, hogy meghatározzam Kurusa kérdéseire a a megfelelô görbült konstans görbületú tereket. A hiperbolikus tér esetén nem volt meglepetés, de a gömbfelületen kiderült, hogy van néhány nagyon speciális kúpmetszet-görbe. 
Ebben a disszertációban kutatásaimnak a [11], [12], és [13] cikkekben már publikált eredményei kerülnek bemutatásra.

Egy $(\mathcal{M}, d)$ projektív-metrikus térben definíció szerint

$\left(D_{1}\right)$ egy kúpmetszet-görbe nem más mint a

$$
\mathcal{C}_{F, \mathcal{H}}^{\varepsilon}:=\left\{X \in \mathbb{R}^{n}: \varepsilon d(X, \mathcal{H})=d(F, X)\right\} \text { halmaz, }
$$

ahol $\mathcal{H}$ egy hipersík, ami a vezérhipersík vagy direktrix, $F \notin \mathcal{H}$ egy pont, ami a fókusz és $\varepsilon>0$ egy szám, a numerikus excentricitás. Egy kúpmetszet-görbéról azt mondjuk, hogy elliptikus, parabolikus vagy hiperbolikus, ha rendre $\varepsilon<1, \varepsilon=1$ and $\varepsilon>1$.

Az $F_{1}, F_{2}$ pontok, a fókuszok, továbbá egy $a \neq d\left(F_{1}, F_{2}\right) / 2$ szám, a sugár, esetén

$\left(D_{2}\right)$ ellipsziodnak (kettő dimenzióban ellipszisnek) hívjuk a

$$
\mathcal{E}_{d ; F_{1}, F_{2}}^{a}:=\left\{E: 2 a=d\left(F_{1}, E\right)+d\left(E, F_{2}\right)\right\}
$$

$\left(D_{3}\right)$ hiperboloidnak (kettô dimenzióban hiperbolának) hívjuk a

$$
\mathcal{H}_{d ; F_{1}, F_{2}}^{a}:=\left\{X: 2 a=\left|d\left(F_{1}, X\right)-d\left(X, F_{2}\right)\right|\right\},
$$

halmazt annak megfelelóen, hogy rendre $a>d\left(F_{1}, F_{2}\right) / 2$ vagy $a<d\left(F_{1}, F_{2}\right) / 2$. A $2 f:=d\left(F_{1}, F_{2}\right)$ érték az excentricitás, és ha az excentricitás eltúnik, akkor az ellipszoidot (ellipszist) gömbfelületnek (körvonalnak) hívjuk. Továbbá, egy ellipszoid (ellipszis) vagy hiperboloid (hiperbola) kúpmetszett, ha kúpmetszet-görbe.

Eltéróen a fenti definícióktól a kvadratikusság definíciója nem hivatkozik a metrikára.

$\left(D_{4}\right)$ Egy kvadratikus görbe azon pontok halmaza, amelyek valamely $\mathfrak{s}$ affin koordinátarendszerben teljesítenek egy

$$
\mathcal{Q}_{\mathfrak{s}}^{\sigma}:=\left\{(x, y):\left\{\begin{array}{ll}
1=x^{2}+\sigma y^{2}, & \text { if } \sigma \in\{-1,1\}, \\
x=y^{2}, & \text { if } \sigma=0,
\end{array}\right\},\right.
$$

egyenletet.

A kvadratikus görbéket kvadrikáknak is nevezik, és egy kvadrikát elliptikusnak, parabolikusnak vagy hiperbolikusnak hívunk, ha rendre $\sigma=1, \sigma=0$ and $\sigma=-1$.

Egy projektív-metrikus $(\mathcal{M}, d)$ tér $\mathcal{S} \subset \mathcal{M}$ részhalmazát egy $C \in \mathcal{M}$ pontra nézve szimmetrikusnak mondunk, ha $X \in \mathcal{S}$ akkor és csak akkor, ha $Y \in \mathcal{S}$, ahol $C$ az $\overline{X Y}$ szakasz metrikus középpontja, vagyis $2 d(X, C)=2 d(C, Y)=d(X, Y)$.

Az 2.1 szakasz, „Kvadratikus, kúpmetszet-görbék a hiperbolikus síkon”, a [11] cikkemen alapul.

Egy kúpmetszet-görbét kvadratikusnak mondunk ha egy $\left(D_{q}\right)$ kvadrikára illeszkedik, vagyis teljesít egy $\bar{a} x^{2}+\bar{b} x y+\bar{c} y^{2}+\bar{d} x+\bar{e} y+\bar{f}=0$ egyenletet, ahol az együtthatók valós számok és $\bar{a} \geq 0$. 
Theorem O.1 ([11]). A hiperbolikus sikon kúpmetszet-görbe nem lehet kvadratikus.

A bizonyítás egy hosszú és trükkös számítás, amely meghatározza a másodlagos egyenlet együtthatóit és ellentmondáshoz vezet.

A 2.2 szakasz, ,,Szimmetrikus kúpmetszet-görbék a hiperbolikus síkon”, a [12] cikkemen alapul.

Egy kúpmetszet-görbét szimmetrikusnak nevezünk, ha szimmetrikus egy pontra nézve.

Theorem $\mathbf{O . 2}([12])$. Hiperbolikus sikon kúpmetszet-görbe nem lehet szimmetrikus.

Ennek igazolására elôször fárasztó számítással meghatározzuk a kúpmetszet-görbe exponenciális egyenletét a Cayley-Klein modellben, majd megvizsgáljuk az ilyen görbe érintőit, feltételezve, hogy a kúpmetszet-görbe szimmetrikus a modell centrumára nézve. Ezután a kúpmetszet-görbe megfelelően megválasztott pontjai azt mutatják, hogy a szimmetria ellentmondásokat idéz elő, ezáltal bizonyítva a tételt.

Az 2.3 szakasz, „Kvadratikus kúpmetszet-görbék a gömbfelületen”, és az 2.4 szakasz, „Szimmetrikus kúpmetszet-görbék a gömbfelületen", alfejezetek a [13] cikkemen alapulnak.

Theorem $\mathbf{O} .3$ ([13]). A gömbfelületen egy kúpmetszet-görbe pontosan akkor kvadratikus, ha a fókuszpontja a direktrix pólusa vagy nem a direktrix pólusa, de a kúpmetszet-görbe parabolikus, vagyis $\varepsilon=1$.

Theorem O.4 ([13]). A gömbfelületen egy kúpmetszet-görbe pontosan akkor szimmetrikus, ha a fókuszpontja a direktrix pólusa.

A 2.5 szakasz, „Kúpmetszet-ellipszisek és kúpmetszet-hiperbolák”, a fenti eredmények egyenes következményeit tartalmazza.

Mivel minden ellipszis és minden hiperbola szimmetrikus a hiperbolikus síkon, ezért minden kúpmetszet-ellipszis és kúpmetszet-hiperbola szimmetrikus kúpmetszet-görbe, tehát a O.4. Tételból következik a következó.

Theorem O.5. Hiperbolikus sikon egyetlen ellipszis vagy hiperbola se kúpmetszet-görbe.

Mivel a gömbfelszínen minden ellipszis és minden hiperbola szimmetrikus, így minden kúpmetszet-ellipszis és kúpmetszet-hiperbola szimmetrikus kúpmetszet-görbe, és így a O.4. Tételból következik a.

Theorem O.6. A gömbfelületen minden kúpmetszet-ellipszis és kúpmetszet-hiperbola körvonal. 


\section{Acknowledgements}

This dissertation is one of the most important parts of my journey of life. During this journey, many people supported and encouraged me for the successful completion of this high academic degree. Furthermore, I would like to thank all those people who made my journey successful and a memorable one. Honestly, words are not enough to express my appreciation to all of them.

First and foremost, this thesis could have been never written without the help of my great supervisor Dr. ÁRPÁD KURUSA. He never hesitated to open discussions and to share his experiences. He taught me how to address research problems and inspired me to explore the scientific way of thinking. I would like to express my sincere gratitude to him for the continuous support in my Ph.D. study and research, for his patience, motivation, enthusiasm, suggestions, and immense knowledge.

I would also like to extend my thanks to the BoLYAi InstituTe of the Faculty of Sciences and Informatics and to the Stipendium Hungaricum Foundation for providing me the opportunity to join Ph.D. studies, and giving access to all research facilities.

I would like to thank DR. BÉLA NAGY for everything he has done for me.

Throughout the years I spent studying mathematics, I have been surrounded by a wonderful set of fellow students, who have constantly motivated me to become better. The town of Szeged contained numerous good friends, with whom I have spent many a welcomely distracting (and improving) evening and weekend.

I cannot imagine ever coming this far without my extended family. They have stood with me through the good times and the bad, and have always provided me with a stable foundation, which is essential in completing any enterprise. I am, and will always be, deeply indebted to my parents, who first kindled my intellectual curiosity, to my sisters, my brothers, and especially to my lovely wife. My dear sons had successfully prevented me from sleeping through late-night flashes of intuition and cheered me up when the writing became too difficult.

I am blessed to have so many good people standing by me. One way or another, big or small, they all had a hand in this thesis, except for the errors - those are mine alone. 


\section{Declaration of Authorship}

I, Ahmed Mohsin Mahdi, declare that this thesis titled, 'Conical Curves in Constant Curvature Planes' and the work presented in it are my own. I confirm that:

- This work was done wholly or mainly while in candidature for a research degree at this University.

- Where any part of this thesis has previously been submitted for a degree or any other qualification at this University or any other institution, this has been clearly stated.

- Where I have consulted the published work of others, this is always clearly attributed.

- Where I have quoted from the work of others, the source is always given. With the exception of such quotations, this thesis is entirely my own work.

- I have acknowledged all main sources of help.

- Where the thesis is based on work done by myself jointly with others, I have made clear exactly what was done by others and what I have contributed myself.

Signed:

Date: 